\title{
Colonization and diversity of aquatic hyphomycetes in relation to decomposition of submerged leaf litter in River Kali (Western Ghats, India)
}

\author{
Sudheep NM ${ }^{1}$ and Sridhar $\mathrm{KR}^{2 *}$ \\ ${ }^{1}$ Department of Plant Science, School of Biological Sciences, Central University of Kerala, Riverside Campus, \\ Padnekkad Nileswaram 671 328, Kerala, India \\ ${ }^{2}$ Department of Biosciences, Mangalore University, Mangalagangotri, Mangalore 574 199, Karnataka, India
}

Sudheep NM, Sridhar KR 2013 - Colonization and diversity of aquatic hyphomycetes in relation to decomposition of submerged leaf litter in River Kali (Western Ghats, India). Mycosphere 4(3), 456-476, Doi 10.5943/mycosphere/4/3/3

\begin{abstract}
Dynamics of leaf chemistry, quantitative studies and decomposition of leaves by aquatic hyphomycetes in the Western Ghats is investigated in this paper. A total of 28 species (range, 1928 spp.) of aquatic hyphomycetes were recovered from natural and submerged (banyan and cashew) leaf litter in Kaiga stream and Kadra dam of the Western Ghats over three seasons (monsoon, post-monsoon and summer) in 12 months of 2008-09. Higher species richness and conidial output was seen during the post-monsoon season and this corroborates with earlier studies. Among the top six species, five were common in different locations of the Western Ghats (Anguillospora longissima, Flagellospora curvula, Lunulospora curvula, Triscelophorus acuminatus and T. monosporus). Among the 12 less frequent species, seven also occurred in low frequency in other locations of the Western Ghats (Clavariopsis aquatica, Dwayaangam cornuta, Flabellospora crassa, F. multiradiata, Ingoldiella hamata, Nawawia filiformis and Tricladium sp.). Leaf litter decomposition resulted in elevation of nitrogen and decrease in phosphorus and total phenolics. Cellulase was higher in banyan than cashew leaves compared to xylanase and pectinase in stream and dam locations. The enzyme activity peaked within one or two weeks and subsequently remained steady with a few exceptions coinciding with increase in total nitrogen, decrease in total phenolics and leaf mass loss. Banyan and cashew leaf litter in Kaiga stream and Kadra dam falls in the slow decomposing category over three seasons $(k, 0.0030-0.00 .0050)$. Decomposition of banyan leaves $(k, 0.0037-0.0050)$ was faster than cashew leaves $(k, 0.0030$ 0.0043 ) in stream as well as dam sites. This was reflected in changes in leaf chemistry (slow decrease of organic carbon, phosphorus, phenolics and gradual increase in nitrogen), low enzyme activity (xylanase and pectinase), low fungal richness, conidial output and fungal diversity in dam location. Leaf mass of banyan and cashew was positively correlated with organic carbon, phosphorus and total phenolics, while negatively correlated with nitrogen and enzyme activity. Negative correlation between phenolics and enzymes reveals that the mass loss was dependent on the quantity and extent of leaching of phenolics. Overall, the assemblage of aquatic hyphomycetes on leaf litter in Kaiga stream and Kadra dam imitates other locations of the Western Ghats with variations in dynamics of leaf chemistry, decomposition and mass loss.
\end{abstract}


Key words - Aquatic hyphomycetes - colonization - dam - decomposition - diversity - enzymes - stream - leaf chemistry - leaf litter - leaf mass loss - Western Ghats

\section{Introduction}

Aquatic hyphomycetes belong to polyphyletic group of fungi called freshwater hyphomycetes, amphibious fungi or Ingoldian fungi (Webster \& Descals 1981, Bärlocher 1992a, Belliveau \& Bärlocher 2005). Plant detritus in streams and rivers constitute up to $50-90 \%$ energy source of aquatic food web (Minshall 1967, Fisher \& Likens 1973, Cummins et al. 1989, Triska \& Cromack 1980). Aquatic hyphomycetes colonize and grow on the decaying leaf litter and produce huge quantity of conidia in lotic habitats (Bärlocher 2009). They produce multiradiate, sigmoid and conventional conidia. Identifications are mainly based on the ontogeny and characteristic morphology of conidia (Ingold 1975, Marvanová 1997, Gulis et al. 2005). The sticky conidial tips facilitate anchoring and colorization of the leaf litter and other organic matter (Webster 1959, Read et al. 1992, Jones 2006, Dang et al. 2007, Kearns \& Bärlocher 2008). Aquatic hyphomycetes release many extracellular enzymes capable to degrade the polysaccharides of leaves, soften and improve palatability for aquatic fauna (Chandrashekar et al. 1991a, Bärlocher 2005, Gessner et al. 2007). Diversity of aquatic hyphomycetes in freshwaters is important for plant litter decomposition and several ecosystem functions (Bärlocher \& Corkum 2003, Duarte et al. 2006). The major developments in the discovery and taxonomic studies on aquatic hyphomycetes from 1880 to 2005 have been documented by Krauss et al. (2011).

The fungal biomass in decaying leaf litter accounts to $63-100 \%$ of total microbial biomass (Gulis \& Suberkropp 2003). Even though bacteria are capable of higher turnover of coarse particulate organic matter (CPOM) in streams, the fungal production is equivalent or higher than bacterial production (Weyers \& Suberkropp 1996). Up to 18-23\% of total detritus mass encompass fungal biomass and $80 \%$ of this biomass will be invested for conidial production in aquatic ecosystem (Suberkropp 1995, Gessner 1997, Methvin \& Suberkropp 2003). Besides increase in biomass, aquatic hyphomycetes produce large numbers of conidia, which will be up to $8 / \mu \mathrm{g}$ detritus dry mass (Gessner 1997). More than $90 \%$ of conidia will be produced mainly by the top 1-4 core group species of aquatic hyphomycetes (frequency of occurrence $\geq 10 \%$ ) (Bärlocher 1992b). Occurrence, interaction and ecosystem functions (e.g. succession, litter mass loss, biomass buildup and detoxification of xenobiotics) of aquatic hyphomycetes in leaf litter of lotic ecosystem are dependent on several factors like assemblage of fungal species, other aquatic microorganisms, aquatic fauna, water qualities and leaf litter qualities (Krauss et al. 2011).

Occurrence and diversity of aquatic hyphomycetes in the Western Ghats have been studied mainly by assessing water, foam and leaf litter (Sridhar et al. 1992, Raviraja et al. 1998a, Rajashekhar \& Kaveriappa 2003). However, a few quantitative studies are available on conidial production by the aquatic hyphomycetes based on bubble chamber incubation (e.g. Raviraja et al. 1996, 1998b, Sridhar et al. 2010). With a few exceptions, detailed studies on water chemistry, leaf litter chemistry, leaf litter enzymes and leaf mass loss are lacking (e.g. Raviraja et al. 1996, 1998b). The main aim of this study is to evaluate the occurrence of aquatic hyphomycetes in the River Kali of the Western Ghats near Kaiga Nuclear Power Station to generate baseline data as this region will emerge in future as an industrial centre. In the current study, aquatic hyphomycetes in naturally submerged leaf litter and immersed leaf litter (banyan and cashew) in two locations of the River Kali (Kaiga stream and Kadra dam) have been investigated. To link the occurrence of aquatic hyphomycetes in leaf litter, water chemistry, leaf litter chemistry, leaf enzymes and leaf mass loss were assessed during different seasons (summer, monsoon and post-monsoon).

\section{Materials and Methods}

\section{Study site}

The River Kali originates in the Western Ghats $\sim 900 \mathrm{~m}$ asl and flows westwards up to 160 $\mathrm{km}$ and joins the Arabian Sea near Karwar City. Kali River has two tributaries (Upper Kaneri and 
Tattihalla) and four dams are built across the rivers Supa, Bommanahalli, Kodasalli, and Kadra for electricity generation. The sampling locations selected for study at the River Kali (Kaiga stream: S1, S2 and S3; Kadra dam, D1, D2 and D3) are situated adjacent to the village Kaiga ( 35 km east of Karwar; $\sim 55^{-70} \mathrm{~m}$ asl; $\left.14^{\circ} 50^{\prime}-14^{\circ} 51^{\prime} \mathrm{N}, 74^{\circ} 24^{\prime}-74^{\circ} 27^{\prime} \mathrm{E}\right)$. The Kaiga stream is a third order stream consists of sandy loam soil and rocky bottom. The Kadra dam receives water from many streamlets passing through wetlands. Average depth of sampling locations of Kaiga stream during sampling period ranged between 1.5 (S1) and $3.5 \mathrm{~m}$ (S3), while in dam sites ranged from $3.6 \mathrm{~m}$ (D3) to $13.8 \mathrm{~m}$ (D2). The sampling stream and dam locations consist of leaf litter, woody litter and roots of many forest trees species mainly Artocarpus heterophyllus, Ficus benghalensis, $F$. racemosa, Syzygium caryophyllatum, Terminalia arjuna, T. paniculata and Xylia xylocarpa.

\section{Water samples}

Water samples were collected five times $(1,2,4,6$ and 8 weeks) in triplicates from each sampling sites during summer (April-May 2008), monsoon (August-September 2008) and postmonsoon (December 2008-January 2009) seasons ( $\mathrm{n}=15$ per season). Water temperature was assessed by mercury thermometer. The $\mathrm{pH}$, electrical conductivity, turbidity and total dissolved solids were assessed at the sampling sites (Water Analyzer 371, Systronics, Gujarat, India). The water samples were fixed on the sampling sites to assess dissolved oxygen by Winkler's method (APHA 1995). Other parameters such as total alkalinity, total hardness, chloride, sulfate, nitrate, silica and magnesium were assessed as per the APHA (1995) methods. The calcium, sodium and potassium of water samples were estimated by flame-emission photometry (MK1/MK3, Systronics, India) (AOAC 1990). The vanadomolybdophosphoric acid method was employed to determine the total phosphorus by measuring the absorbance at $420 \mathrm{~nm}$ using $\mathrm{KH}_{2} \mathrm{PO}_{4}$ as standard (AOAC 1990).

\section{Leaf litter}

Naturally deposited decomposing leaf litter from each sampling site in three replicates during 1, 2, 4, 6 and 8 weeks in each season was collected ( $\mathrm{n}=15$ per season). After rinsing in water, different leaves were packed and punched into disks $(1.5 \mathrm{~cm}$ diam.) using cork-borer. The disks were assessed for the colonization of aquatic hyphomycetes by bubble chamber incubation. The leaf disks (5-8 disks/sample) were incubated in $150 \mathrm{~mL}$ of sterile distilled water in $250 \mathrm{~mL}$ Erlenmeyer flasks. Water in flasks was aerated though Pasteur pipettes by an aquarium pump for up to $48 \mathrm{~h}$ $\left(23 \pm 2^{\circ} \mathrm{C}\right)$. Aerated water was filtered through a Millipore filters $(5 \mu \mathrm{m})$ and stained with aniline blue in lactophenol $(0.1 \%)$. Each stained filter was cut into half, mounted on a microscope slide with lactic acid, and the conidia of aquatic hyphomycetes trapped on the filters were identified based on monographs and primary literature (Ingold 1975, Carmichael et al. 1980, Webster \& Descals 1981, Nawawi 1985, Marvanová 1997, Santos-Flores \& Betancourt-López 1997, Gulis et al. 2005).

\section{Fungi}

To assess the pattern of fungal colonization on immersed leaf litter, senescent and freshly fallen leaves of banyan (Ficus Benghalensis Linn.) and cashew (Anacardium occidentale L.) were collected from a single tree from the Kaiga forest during February 2008. They were air-dried up to 3-4 weeks $\left(30^{\circ} \mathrm{C}\right)$ and soaked in water overnight and punched into disks $(1.5 \mathrm{~cm})$. Up to $15-20$ disks were packed per nylon mesh bag $(15 \times 15 \mathrm{~cm}$; mesh size, $1 \mathrm{~mm})$ to introduce into the stream and dam locations. About 20 bags were prepared with pre-weighed disks to determine the mass loss. A total of 80 bags (numbered with plastic tags) of each leaf litter in four sets were immersed in sampling sites by tying the bags to nylon ropes and the ropes were fastened to nearby root or tree trunks. Out of them, leaf disks of about 20 bags each were used to assess the fungal colonization by bubble chamber incubation, leaf chemistry, leaf enzymes and leaf mass loss on sampling 1, 2, 4, 6 and 8 weeks in each season. 


\section{Leaf chemistry}

The leaf disks were harvested during 1, 2, 4, 6 and 8 weeks were dried at $40-45^{\circ} \mathrm{C}$ and organic carbon, nitrogen, phosphorus, total phenolics and enzymes were analyzed.

\section{Organic carbon}

Walkley and Black's rapid titration method was employed to quantify organic carbon in leaf disks (Jackson 1973). Fifty $\mathrm{mg}$ leaf powder was taken in a $500 \mathrm{~mL}$ Erlenmeyer flask, $1 \mathrm{~N} \mathrm{~K}_{2} \mathrm{Cr}_{2} \mathrm{O}_{7}$ $(5 \mathrm{~mL})$ was added, after $5 \mathrm{~min} 90 \% \mathrm{H}_{2} \mathrm{SO}_{4}(15 \mathrm{~mL})$ was added and digested $(30 \mathrm{~min})$. Distilled water $(100 \mathrm{~mL})$ was added to the digested sample followed by addition of orthophosphate $(85 \% ; 5$ $\mathrm{mL})$ and the contents were titrated against ferrous ammonium sulphate $(0.5 \mathrm{~N})$ using diphenylamine indicator $(0.5 \mathrm{~mL})$.

\section{Nitrogen}

The dried leaf powder of banyan and cashew was digested for the estimation of nitrogen. Leaf samples $(100 \mathrm{mg})$ with catalytic mixture $(1 \mathrm{~g})$ were digested in concentrated $\mathrm{H}_{2} \mathrm{SO}_{4}(10 \mathrm{~mL})$ in a Kjeldahl flask (30 mL capacity) on a hot sand bath. After cooling, the contents were transferred to $100 \mathrm{~mL}$ volumetric flask, the Kjeldahl flask was rinsed twice with $20 \mathrm{~mL}$ distilled water and transferred to the volumetric flask and made up the volume to $100 \mathrm{~mL}$ (Chale 1993). The digest (10 $\mathrm{mL})$ was transferred to micro-Kjeldahl distillation flask, $\mathrm{NaOH}(40 \% ; 10 \mathrm{~mL})$ was added and distilled. The liberated ammonia was collected in boric acid $(2 \% ; 10 \mathrm{~mL})$ containing mixed indicator until attain $25 \mathrm{~mL}$ volume and titrated against dilute $\mathrm{HCl}(0.01 \mathrm{~N})$ (APHA 1995).

\section{Phosphorus}

Phosphorus was measured colorimetrically employing vanadomolybdo-phosphoric acid method (AOAC 1990). The banyan and cashew leaf samples were digested in tri-acid mixture $\left(\mathrm{HNO}_{3}, \mathrm{H}_{2} \mathrm{SO}_{4}\right.$ and $\mathrm{HClO}_{3}$ : 10:1:4). The digest was made up to $50 \mathrm{~mL}$ with Milli- $Q$ water. The digest $(3 \mathrm{~mL})$ was mixed with vanado-molybdate reagent $(10 \mathrm{~mL})$, mixed thoroughly and made the volume to $50 \mathrm{~mL}$. The absorbance of yellow color developed due to formation of vanadomolybdophosphoric acid was measured after $10 \mathrm{~min}$ at $420 \mathrm{~nm}$ (UV-VIS Spectrophotometer118, SYSTRONICS, Ahmedabad, Gujarat, India) using reagent blank as the reference. Known concentrations of $\mathrm{KH}_{2} \mathrm{PO}_{4}$ served as standard.

\section{Phenolics}

The total phenolics of banyan and cashew leaf powders was determined by Rossett et al. (1982). Subsamples of leaf powder $(100 \mathrm{mg})$ were extracted twice with methanol $(50 \% ; 5 \mathrm{~mL})$ at $90^{\circ} \mathrm{C}$ for $10 \mathrm{~min}$ in centrifuge tubes capped with marble. The pooled extracts were made up to 10 $\mathrm{mL}$, mixed and $0.5 \mathrm{~mL}$ extract was diluted with distilled water $(0.5 \mathrm{~mL})$, treated with $2 \% \mathrm{Na}_{2} \mathrm{CO}_{3}$ in $0.1 \mathrm{~N} \mathrm{NaOH}(5 \mathrm{~mL})$. After $10 \mathrm{~min}$, of Folin-Ciocalteus reagent $(0.5 \mathrm{~mL})$ (diluted 1:1 with distilled water) was added and the absorbance was read at $725 \mathrm{~nm}$. Calibration curve was prepared by treating known concentration of tannic acid solutions similar to that of the sample as standard.

\section{Enzymes}

Harvested leaf disks $(1,2,4,6,8$ weeks) in five replicates were freeze-dried (OPERON, OPR- FDB-5003, Korea), powdered, and the enzymes (cellulase, xylanase and pectinase) were estimated colorimetrically (Nelson 1944, Somogyi 1952). Briefly, leaf powder (100 mg) were wetted with sterile distilled water $(25 \mathrm{~mL})$ for $30 \mathrm{~min}$, filtered through Whatman \# 1 filter paper, filtrates $(0.5 \mathrm{~mL})$ were mixed with acetate buffer $(1 \mathrm{~mL})$ and substrate $(0.5 \%$ carboxymethyl cellulose or xylan or polygalacturonic acid; $1 \mathrm{~mL}$ ) with a drop of toluene (to avoid bacterial growth) and incubated $(1 \mathrm{~h})$. The samples were boiled in water bath $(10 \mathrm{~min})$ for inactivation of enzymes, on cooling room temperature, Somogy's reagent $(1 \mathrm{~mL})$ and Nelson's reagent $(0.5 \mathrm{~mL})$ were added. The liberated reducing sugars were estimated spectrophotometrically at $620 \mathrm{~nm}$ with D-glucose or 
D-xylose or D-galacturonic acid as standard. A boiled extract served as a blank and the enzyme activity was expressed as $\mu \mathrm{g} / \mathrm{mL} / \mathrm{h}$.

\section{Leaf mass loss}

Pre-weighed leaf disks in randomly-sampled litter bags were harvested and rinsed to remove sediment and debris. The mass loss was determined by comparing initial mass (100\%) before exposure and remaining mass after air-drying and corrected by exposure to $100^{\circ} \mathrm{C}$ for $24 \mathrm{~h}$. Extra samples were used to create a correction factor for air dry mass-to-oven dry mass. The exponential decay coefficient, $k$ was estimated by linear regression of ln-transformed data.

\section{Data analysis}

The frequency of occurrence $(\%)$ and relative abundance $(\%)$ of each fungus on natural, banyan and cashew leaves were determined:

Frequency of occurrence $(\%)=[($ Number of leaf samples colonized $) \div($ Total Leaf samples examined) $] \times 100$

Relative abundance $(\%)=[($ Frequency of occurrence of a specific fungus $) \div($ Total of frequency of occurrence all fungi) $] \times 100$

To compare the richness of fungi in natural, banyan and cashew leaf samples based on number of isolations and number of samples assessed, the expected number of species was calculated by rarefaction indices (Ludwig \& Reynolds 1988). The expected number of species, $E_{(s)}$, in a random sample of $n$ isolations taken from a total population of $N$ isolations was estimated:

$$
E_{(s)}=\sum_{i=1}^{s}\left\{1-\left[\left(\begin{array}{cc}
N-n_{i} \\
n
\end{array}\right) /\left(\begin{array}{l}
N \\
n
\end{array}\right)\right]\right\}
$$

(where, $n_{i}$ is the number of fungal isolations of the $i$ th species).

The Shannon's diversity $\left(H^{\prime}\right)$ (Magurran 1988) and Pielou's evenness $\left(J^{\prime}\right)$ (Pielou 1975) of aquatic hyphomycetes in natural, banyan and cashew leaf samples were calculated:

$$
H^{\prime}=-\sum\left(p_{i} \ln p_{i}\right)
$$

(where, $p_{i}$ is the proportions of individual that species $i$ contributes to the total number of individuals)

$$
J^{\prime}=\left(H^{\prime} \div H^{\prime}{ }_{\max }\right)
$$

(where, $H_{\text {max }}^{\prime}=\ln S$ )

Sorensen's similarity coefficient $\left(C_{S}\right)(\%)$ of aquatic hyphomycetes among natural, banyan and cashew leaves in Kaiga stream and Kadra dam was calculated based on Chao et al. (2005):

$$
C_{S}(\%)=(2 \times c \div a+b) \times 100
$$

(where, $a$ is total number of species in location $1 ; b$ is total number of species in location 2 ; $c$ is number of species common to locations 1 and 2)

Exponential decay coefficient, $k$, were estimated for decomposition of banyan and cashew leaves in Kaiga stream and Kadra dam based on the exponential decay model proposed by Petersen and Cummins (1974) using MATLAB 6.5:

$$
W_{t}=W_{0} \cdot e^{-k t}
$$

(where $W_{0}$ is the percentage of the initial leaf mass; $W_{t}$ is the percentage of leaf mass remaining after time $t$ (days) and $k$ is a decay coefficient per day).

The time (days) required for the decomposition of half of the initial leaf mass $\left(t_{50}\right)$ was determined:

$t_{50}=\ln 2 / k$

The leaf decay coefficient $(k)$ of Kaiga stream vs. Kadra dam was assessed by $t$-test using Statistica version 8.0. (StatSoft Inc. 2008).

The relationship between mass loss of banyan and cashew leaves vs. leaf chemistry (organic carbon, nitrogen, phosphorus and total phenolics) and leaf enzymes (cellulase, xylanase and 
pectinase) was assessed by Pearson's correlation (parameters: $\mathrm{p}$ values, two tailed; confidence intervals, 95\%) (SPSS 6.0 Windows Student Version 3.5).

\section{Results}

\section{Water parameters}

The physicochemical data of water samples of Kaiga stream and Kadra dam locations in three seasons are summarized in Table 1. Many parameters differed substantially among the sites and seasons. For instance, the temperature and chloride were least during post-monsoon season, while the $\mathrm{pH}$ was slightly alkaline and it was least during summer in both locations. Sodium content also attained least during summer. The dissolved oxygen was higher in stream than dam (8-8.3 vs. 6.5-7 mg/L). The total alkalinity, total hardness, silica and magnesium contents were least during monsoon in both locations.

\section{Fungal colonization}

Occurrence and relative abundance of aquatic hyphomycetes on natural and submerged leaf litter have been given in Tables 2, 3 and 4. Banyan leaves consists of highest number of species (29 spp.) than natural leaves (23 spp.) and cashew leaves (19 spp.). Six species (Anguillospora longissima, Flagellospora curvula, Lunulospora curvula, Triscelophorus acuminatus, T. konajensis and T. monosporus) were among the top 10 species on natural leaves and submerged leaves in both locations. Twelve species (Alatospora acuminata, Clavariopsis aquatica, Dimorphospora foliicola, Dwayaangam cornuta, Flabellospora crassa, F. multiradiata, Helicomyces scandens, Ingoldiella hamata, Nawawia filiformis, Synnematophora constricta, Tricladium sp. and Tumularia aquatica) were below 5\% frequency of occurrence either in natural leaves and or in submerged leaves. However, the natural leaves consists of only three species with $<5 \%$ frequency of occurrence compared to banyan (6 spp.) and cashew (7 spp.) leaves.
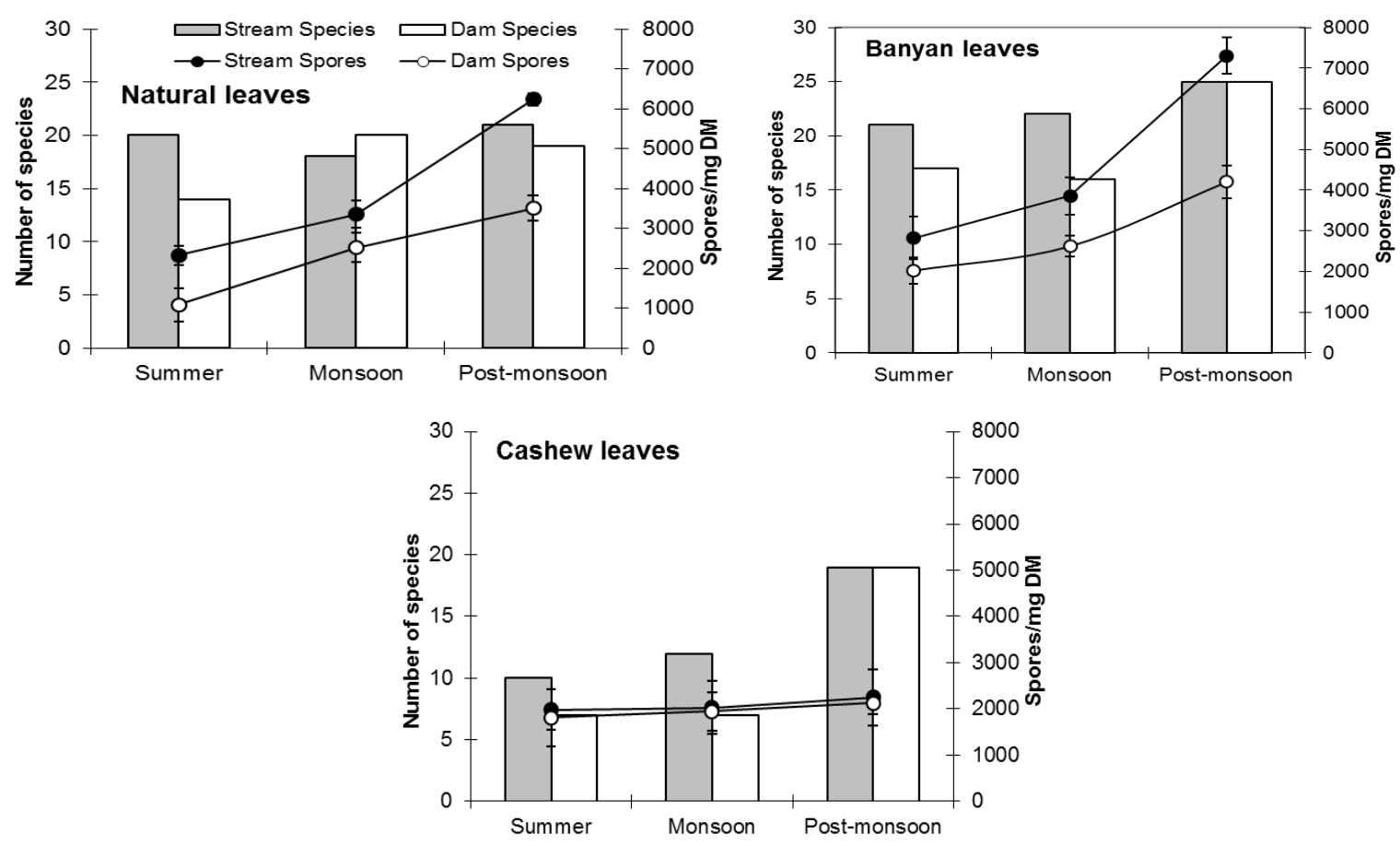

Fig. 1 - Species richness and conidial output of aquatic hyphomycetes in natural and immersed leaves (banyan and cashew) in Kaiga stream and Kadra dam. 
Table 1 Physical and chemical properties of Kaiga stream and Kadra dam (in parenthesis) ( $\mathrm{n}=15$, mean \pm SD)

\begin{tabular}{|c|c|c|c|}
\hline & Summer & Monsoon & Post-monsoon \\
\hline Temperature $\left({ }^{\circ} \mathrm{C}\right)$ & $\begin{array}{l}25.6 \pm 3.7 \\
(32.4 \pm 1.0)\end{array}$ & $\begin{array}{l}24.9 \pm 2.1 \\
(32.1 \pm 1.2)\end{array}$ & $\begin{array}{l}21.1 \pm 2.0 \\
(31.1 \pm 1.6)\end{array}$ \\
\hline $\mathrm{pH}$ & $\begin{array}{l}7.3 \pm 0.3 \\
(7.1 \pm 0.3)\end{array}$ & $\begin{array}{l}7.8 \pm 0.4 \\
(7.5 \pm 0.3)\end{array}$ & $\begin{array}{l}7.5 \pm 0.4 \\
(7.4 \pm 0.4)\end{array}$ \\
\hline Conductivity $(\mu \mathrm{S} / \mathrm{cm})$ & $\begin{array}{l}66.5 \pm 12.3 \\
(65.8 \pm 14.8)\end{array}$ & $\begin{array}{l}52.5 \pm 8.7 \\
(75.1 \pm 10.7)\end{array}$ & $\begin{array}{l}67.5 \pm 16.7 \\
(90.1 \pm 20.5)\end{array}$ \\
\hline Turbidity (NTU) & $\begin{array}{l}2.9 \pm 0.4 \\
(3.1 \pm 0.4)\end{array}$ & $\begin{array}{l}3.3 \pm 1.4 \\
(12.3 \pm 2.3)\end{array}$ & $\begin{array}{l}2.7 \pm 0.7 \\
(4.1 \pm 1.7)\end{array}$ \\
\hline Total dissolved solids (mg/L) & $\begin{array}{l}33.9 \pm 6.6 \\
(32.7 \pm 6.2)\end{array}$ & $\begin{array}{l}26.6 \pm 4.3 \\
(39.4 \pm 8.2)\end{array}$ & $\begin{array}{l}34.4 \pm 7.9 \\
(46.9 \pm 11.6)\end{array}$ \\
\hline Dissolved oxygen (mg/L) & $\begin{array}{l}8.0 \pm 0.4 \\
(6.5 \pm 0.3)\end{array}$ & $\begin{array}{l}8.2 \pm 0.3 \\
(7.0 \pm 0.4)\end{array}$ & $\begin{array}{l}8.3 \pm 0.2 \\
(6.8 \pm 0.3)\end{array}$ \\
\hline Total alkalinity (mg/L) & $\begin{array}{l}23.3 \pm 4.7 \\
(24.0 \pm) 3.1\end{array}$ & $\begin{array}{l}16.3 \pm 2.1 \\
(23.4 \pm 5.1)\end{array}$ & $\begin{array}{l}25.1 \pm 4.9 \\
(31.5 \pm 5.4)\end{array}$ \\
\hline Total hardness (as $\mathrm{CaCO}_{3}$ ) & $\begin{array}{l}27.8 \pm 8.1 \\
(27.8 \pm 3.1)\end{array}$ & $\begin{array}{l}18.4 \pm 2.3 \\
(26.1 \pm 6.0)\end{array}$ & $\begin{array}{l}26.4 \pm 7.6 \\
(28.6 \pm 5.0)\end{array}$ \\
\hline Chloride (mg/L) & $\begin{array}{l}5.6 \pm 1.2 \\
(5.7 \pm 1.5)\end{array}$ & $\begin{array}{l}4.6 \pm 1.1 \\
(5.1 \pm 0.8)\end{array}$ & $\begin{array}{l}4.3 \pm 0.8 \\
(4.9 \pm 1.1)\end{array}$ \\
\hline Sulfate $(\mathrm{mg} / \mathrm{L})$ & $\begin{array}{l}2.9 \pm 0.3 \\
(2.7 \pm 0.1)\end{array}$ & $\begin{array}{l}2.3 \pm 0.8 \\
(2.9 \pm 0.4)\end{array}$ & $\begin{array}{l}2.3 \pm 0.6 \\
(3.0 \pm 0.3)\end{array}$ \\
\hline Nitrate $(\mathrm{mg} / \mathrm{L})$ & $\begin{array}{l}1.3 \pm 0.2 \\
(1.4 \pm 0.2)\end{array}$ & $\begin{array}{l}1.3 \pm 0.2 \\
(1.2 \pm 0.1)\end{array}$ & $\begin{array}{l}1.3 \pm 0.3 \\
(1.2 \pm 0.1)\end{array}$ \\
\hline Silica $(\mathrm{mg} / \mathrm{L})$ & $\begin{array}{l}11.6 \pm 2.3 \\
(10.3 \pm 1.7)\end{array}$ & $\begin{array}{l}9.1 \pm 3.6 \\
(9.8 \pm 2.0)\end{array}$ & $\begin{array}{l}9.4 \pm 1.6 \\
(10.5 \pm 1.5)\end{array}$ \\
\hline Magnesium (mg/L) & $\begin{array}{l}4.4 \pm 2.0 \\
(3.8 \pm 0.7)\end{array}$ & $\begin{array}{l}2.6 \pm 0.8 \\
(3.2 \pm 0.9)\end{array}$ & $\begin{array}{l}3.8 \pm 0.9 \\
(3.3 \pm 0.9)\end{array}$ \\
\hline Calcium (mg/L) & $\begin{array}{l}3.9 \pm 0.4 \\
(4.8 \pm 0.4)\end{array}$ & $\begin{array}{l}3.6 \pm 1.6 \\
(5.6 \pm 2.3)\end{array}$ & $\begin{array}{l}4.4 \pm 1.8 \\
(6.0 \pm 0.7)\end{array}$ \\
\hline Sodium $(\mathrm{mg} / \mathrm{L})$ & $\begin{array}{l}3.6 \pm 1.7 \\
(3.2 \pm 0.9)\end{array}$ & $\begin{array}{l}3.7 \pm 1.1 \\
(4.1 \pm 1.4)\end{array}$ & $\begin{array}{l}4.4 \pm 2.1 \\
(6.4 \pm 2.2)\end{array}$ \\
\hline Potassium (mg/L) & $\begin{array}{l}0.2 \pm 0.04 \\
(1.2 \pm 0.02)\end{array}$ & $\begin{array}{l}0.4 \pm 0.04 \\
(0.5 \pm 0.2)\end{array}$ & $\begin{array}{l}0.4 \pm 0.04 \\
(0.3 \pm 0.1)\end{array}$ \\
\hline Phosphate $(\mu \mathrm{g} / \mathrm{L})$ & $\begin{array}{l}10.2 \pm 3.3 \\
(10.1 \pm 3.4)\end{array}$ & $\begin{array}{l}6.6 \pm 0.7 \\
(6.5 \pm 1.2)\end{array}$ & $\begin{array}{l}6.8 \pm 0.4 \\
(5.5 \pm 0.7)\end{array}$ \\
\hline
\end{tabular}

Number of species on natural leaves was highest during post-monsoon in stream, while during monsoon in dam (Fig. 1, Table 2). In both locations in natural leaves, the conidial output was highest during post-monsoon. The species richness and conidial output were highest during postmonsoon season in banyan and cashew leaves in both locations (Table 3, 4). Rarefaction indices revealed that the banyan leaves in stream possess highest species richness (43 spp.) out of a 75 random samples followed by natural leaves (42 spp.) in Kaiga stream, while it was least in cashew leaves of dam (30 spp.) (Table 5). Banyan leaves of stream showed the highest and extended species richness curve, while it was the lowest and truncated in cashew leaves of dam (Fig. 2). The Shannon diversity also followed similar pattern of rarefaction indices. The Sorenson's similarity was highest between natural leaves of stream and dam locations (100\%), so also in cashew leaves of stream and dam (100\%) (Table 6). In rest of the combinations, the similarity was ranged between $80 \%$ and $98.2 \%$. 
Table 2 Number of occurrences (out of 15 samples of natural leaves), frequency of occurrence (FO $\%$ ) and relative abundance (RA \%) of aquatic hypohomycetes fungi on naturally deposited leaf litter during summer, monsoon and post-monsoon in Kaiga stream and Kadra dam (in parenthesis)

\begin{tabular}{|c|c|c|c|c|c|}
\hline & Summer & Monsoon & Post-monsoon & FO $(\%)$ & RA (\%) \\
\hline Lunulospora curvula Ingold & $11(8)$ & $11(9)$ & $13(5)$ & $\begin{array}{l}77.7 \\
(48.9)\end{array}$ & $\begin{array}{l}9.2 \\
(11.6)\end{array}$ \\
\hline Triscelophorus monosporus Ingold & $14(8)$ & $9(4)$ & $11(5)$ & $\begin{array}{l}75.5 \\
(37.7)\end{array}$ & $\begin{array}{l}9.0 \\
(8.9)\end{array}$ \\
\hline Triscelophorus acuminatus Nawawi & $9(6)$ & $11(7)$ & $8(3)$ & $\begin{array}{l}62.2 \\
(35.5)\end{array}$ & $\begin{array}{l}7.4 \\
(8.4)\end{array}$ \\
\hline $\begin{array}{l}\text { Anguillospora longissima (Sacc. \& P. } \\
\text { Syd.) Ingold }\end{array}$ & $5(2)$ & $6(8)$ & $9(10)$ & $\begin{array}{l}44.4 \\
(44.4)\end{array}$ & $\begin{array}{l}5.3 \\
(10.5)\end{array}$ \\
\hline $\begin{array}{l}\text { Triscelophorus konajensis K.R. Sridhar } \\
\& \text { Kaver. }\end{array}$ & $5(2)$ & $8(6)$ & $12(5)$ & $\begin{array}{l}55.5 \\
(28.9)\end{array}$ & $\begin{array}{l}6.6 \\
(6.9)\end{array}$ \\
\hline Flagellospora curvula Ingold & $9(8)$ & $6(4)$ & $6(2)$ & $\begin{array}{l}46.6 \\
(31.1)\end{array}$ & $\begin{array}{l}5.5 \\
(7.4)\end{array}$ \\
\hline Lunulospora cymbiformis K. Miura & $6(2)$ & $5(1)$ & $11(8)$ & $\begin{array}{l}48.8 \\
(24.4)\end{array}$ & $\begin{array}{l}5.8 \\
(5.8)\end{array}$ \\
\hline Tripospermum myrti (Lind) S. Hughes & $5(2)$ & $2(6)$ & $5(8)$ & $\begin{array}{l}26.6 \\
(35.5)\end{array}$ & $\begin{array}{l}3.2 \\
(8.4)\end{array}$ \\
\hline Clavariopsis aquatica de Wild. & $6(2)$ & 8 & 10 & $\begin{array}{l}53.3 \\
(4.4)\end{array}$ & $\begin{array}{l}6.3 \\
(1.1)\end{array}$ \\
\hline $\begin{array}{l}\text { Synnematophora constricta K.R. Sridhar } \\
\text { \& Kaver. }\end{array}$ & $3(1)$ & $8(2)$ & $9(2)$ & $\begin{array}{l}44.4 \\
(11.1)\end{array}$ & $\begin{array}{l}5.3 \\
(2.6)\end{array}$ \\
\hline Flabellospora verticillata Alas. & $6(1)$ & $3(1)$ & $9(4)$ & $\begin{array}{l}40.0 \\
(13.3)\end{array}$ & $\begin{array}{l}4.7 \\
(3.2)\end{array}$ \\
\hline Anguillospora crassa Ingold & 5 & $8(3)$ & $5(2)$ & $\begin{array}{l}40.0 \\
(11.1)\end{array}$ & $\begin{array}{l}4.7 \\
(2.6)\end{array}$ \\
\hline Dimorphospora foliicola Tubaki & 5 & $3(2)$ & $8(2)$ & $\begin{array}{l}35.5 \\
(8.9)\end{array}$ & $\begin{array}{l}4.2 \\
(2.1)\end{array}$ \\
\hline Flabellospora multiradiata Nawawi & $3(1)$ & 6 & $8(2)$ & $\begin{array}{l}37.7 \\
(6.7)\end{array}$ & $\begin{array}{l}4.5 \\
(1.6)\end{array}$ \\
\hline Campylospora chaetocladia Ranzoni & (2) & $7(2)$ & $6(1)$ & $\begin{array}{l}28.9 \\
(11.1)\end{array}$ & $\begin{array}{l}3.4 \\
(2.6)\end{array}$ \\
\hline Lateriramulosa uni-inflata Matsush. & $4(2)$ & 3 & $6(3)$ & $\begin{array}{l}28.9 \\
(11.1)\end{array}$ & $\begin{array}{l}3.4 \\
(11.1)\end{array}$ \\
\hline Flabellospora crassa Alas. & - & $4(2)$ & $8(3)$ & $\begin{array}{l}26.6 \\
(11.1)\end{array}$ & $\begin{array}{l}3.2 \\
(2.6)\end{array}$ \\
\hline Clavariana aquatica Nawawi & 2 & (3) & $5(2)$ & $\begin{array}{l}15.5 \\
(11.1)\end{array}$ & $\begin{array}{l}1.8 \\
(2.6)\end{array}$ \\
\hline Cylinodrocarpon sp. & 2 & $5(2)$ & (3) & $\begin{array}{l}15.5 \\
(11.1)\end{array}$ & $\begin{array}{l}1.8 \\
(2.6)\end{array}$ \\
\hline Lunulospora sp. & 2 & (3) & 5 & $\begin{array}{l}15.5 \\
(6.7)\end{array}$ & $\begin{array}{l}1.8 \\
(1.6)\end{array}$ \\
\hline Ingoldiella hamata D.E. Shaw & 2 & (1) & 5 & $\begin{array}{l}15.5 \\
(2.2)\end{array}$ & $\begin{array}{l}1.8 \\
(0.5)\end{array}$ \\
\hline $\begin{array}{l}\text { Tumularia aquatica (Ingold) Descals \& } \\
\text { Marvanová }\end{array}$ & - & (2) & $2(3)$ & $\begin{array}{l}4.4 \\
(11.1)\end{array}$ & $\begin{array}{l}0.5 \\
(2.6)\end{array}$ \\
\hline Nawawia filiformis (Nawawi) Marvanová & 2 & (2) & - & $\begin{array}{l}4.4 \\
(4.4)\end{array}$ & $\begin{array}{l}0.5 \\
(1.1)\end{array}$ \\
\hline
\end{tabular}

\section{Changes in leaf chemistry}

The initial organic carbon content was higher in cashew than banyan leaves (Fig. 3). It dropped less quickly in stream banyan leaves during summer, while more quickly in cashew leaves in dam during summer and stream during post-monsoon. At the end of 56 days, both leaf litter attained more or less same level of organic carbon. 
Table 3 Number of occurrences (out of 15 bags with leaf disks), frequency of occurrence (FO \%) and relative abundance (RA \%) of aquatic hypohomycetes on submerged leaf disks of banyan (Ficus benghalensis) during summer, monsoon and post-monsoon in Kaiga stream and Kadra dam (in parenthesis)

\begin{tabular}{|c|c|c|c|c|c|}
\hline & Summer & Monsoon & Post-monsoon & FO $(\%)$ & RA (\%) \\
\hline Lunulospora curvula Ingold & $10(8)$ & $13(7)$ & $14(11)$ & $\begin{array}{l}82.1 \\
(57.7)\end{array}$ & $\begin{array}{l}11.1 \\
(12.0)\end{array}$ \\
\hline Triscelophorus acuminatus Nawawi & $8(7)$ & $8(10)$ & $9(6)$ & $\begin{array}{l}55.5 \\
(51.1)\end{array}$ & $\begin{array}{l}7.5 \\
(10.7)\end{array}$ \\
\hline Flagellospora curvula Ingold & $9(3)$ & $8(3)$ & $10(7)$ & $\begin{array}{l}59.9 \\
(28.9)\end{array}$ & $\begin{array}{l}8.1 \\
(6.0)\end{array}$ \\
\hline Triscelophorus monosporus Ingold & $7(2)$ & $5(3)$ & $9(10)$ & $\begin{array}{l}46.6 \\
(33.3)\end{array}$ & $\begin{array}{l}6.3 \\
(6.9)\end{array}$ \\
\hline $\begin{array}{l}\text { Anguillospora longissima (Sacc. \& P. } \\
\text { Syd.) Ingold }\end{array}$ & $6(2)$ & $9(4)$ & $9(5)$ & $\begin{array}{l}53.3 \\
(24.4)\end{array}$ & $\begin{array}{l}7.2 \\
(5.1)\end{array}$ \\
\hline Anguillospora crassa Ingold & $2(2)$ & $3(4)$ & $9(7)$ & $\begin{array}{l}31.1 \\
(28.9)\end{array}$ & $\begin{array}{l}4.2 \\
(6.0)\end{array}$ \\
\hline Clavariana aquatica Nawawi & 3 & $5(2)$ & $8(7)$ & $\begin{array}{l}35.5 \\
(20.0)\end{array}$ & $\begin{array}{l}4.8 \\
(4.2)\end{array}$ \\
\hline $\begin{array}{l}\text { Triscelophorus konajensis K.R. Sridhar } \\
\& \text { Kaver. }\end{array}$ & 2 & $1(3)$ & $9(7)$ & $\begin{array}{l}26.6 \\
(22.2)\end{array}$ & $\begin{array}{l}3.6 \\
(4.6)\end{array}$ \\
\hline Tripospermum myrti (Lind) S. Hughes & (2) & $3(5)$ & $5(6)$ & $\begin{array}{l}17.8 \\
(28.9)\end{array}$ & $\begin{array}{l}2.4 \\
(6.0)\end{array}$ \\
\hline Flabellospora verticillata Alas. & $1(3)$ & 2 & $5(6)$ & $\begin{array}{l}17.8 \\
(20.0)\end{array}$ & $\begin{array}{l}2.4 \\
(4.2)\end{array}$ \\
\hline Dimorphospora foliicola Tubaki & $5(1)$ & 2 & $6(2)$ & $\begin{array}{l}28.9 \\
(6.7)\end{array}$ & $\begin{array}{l}3.9 \\
(1.4)\end{array}$ \\
\hline Flabellospora crassa Alas. & - & $3(1)$ & $5(7)$ & $\begin{array}{l}17.8 \\
(17.8)\end{array}$ & $\begin{array}{l}2.4 \\
(3.7)\end{array}$ \\
\hline Campylospora parvula Kuzuha & $2(1)$ & 3 & $5(4)$ & $\begin{array}{l}22.2 \\
(11.1)\end{array}$ & $\begin{array}{l}3.0 \\
(2.3)\end{array}$ \\
\hline Clavariopsis aquatica de Wild. & 2 & (5) & $4(4)$ & $\begin{array}{l}13.3 \\
(20.0)\end{array}$ & $\begin{array}{l}1.8 \\
(4.2)\end{array}$ \\
\hline Cylinodrocarpon sp. & 2 & (3) & $4(2)$ & $\begin{array}{l}13.3 \\
(11.1)\end{array}$ & $\begin{array}{l}1.8 \\
(2.3)\end{array}$ \\
\hline Campylospora chaetocladia Ranzoni & $3(2)$ & $3(5)$ & 8 & $\begin{array}{l}31.1 \\
(15.5)\end{array}$ & $\begin{array}{l}4.2 \\
(3.2)\end{array}$ \\
\hline Lunulospora sp. & (2) & $3(1)$ & $8(6)$ & $\begin{array}{l}24.4 \\
(20.0)\end{array}$ & $\begin{array}{l}3.3 \\
(4.2)\end{array}$ \\
\hline Lunulospora cymbiformis K. Miura & 5 & $4(2)$ & $6(3)$ & $\begin{array}{l}33.3 \\
(11.1)\end{array}$ & $\begin{array}{l}4.5 \\
(2.3)\end{array}$ \\
\hline $\begin{array}{l}\text { Tumularia aquatica (Ingold) Descals \& } \\
\text { Marvanová }\end{array}$ & $1(1)$ & - & $8(3)$ & $\begin{array}{l}20.0 \\
(8.9)\end{array}$ & $\begin{array}{l}2.7 \\
(1.9)\end{array}$ \\
\hline Nawawia filiformis (Nawawi) Marvanová & (2) & 4 & 6 & $\begin{array}{l}22.2 \\
(4.4)\end{array}$ & $\begin{array}{l}3.0 \\
(0.9)\end{array}$ \\
\hline Ingoldiella hamata D.E. Shaw & (2) & 5 & $2(3)$ & $\begin{array}{l}15.5 \\
(11.1)\end{array}$ & $\begin{array}{l}2.1 \\
(2.3)\end{array}$ \\
\hline Lateriramulosa uni-inflata Matsush. & (1) & 2 & $4(2)$ & $\begin{array}{l}13.3 \\
(6.7)\end{array}$ & $\begin{array}{l}1.8 \\
(1.4)\end{array}$ \\
\hline $\begin{array}{l}\text { Synnematophora constricta K.R. Sridhar } \\
\text { \& Kaver. }\end{array}$ & 2 & $4(2)$ & (1) & $\begin{array}{l}13.3 \\
(6.7)\end{array}$ & $\begin{array}{l}1.8 \\
(1.4)\end{array}$ \\
\hline Flabellospora multiradiata Nawawi & - & 4 & $2(1)$ & $\begin{array}{l}13.3 \\
(2.2)\end{array}$ & $\begin{array}{l}1.8 \\
(0.5)\end{array}$ \\
\hline Alatospora acuminata Ingold & 1 & 4 & (2) & $\begin{array}{l}11.1 \\
(4.4)\end{array}$ & $\begin{array}{l}1.5 \\
(0.9)\end{array}$ \\
\hline Tricladium sp. & 2 & - & $3(1)$ & $\begin{array}{l}11.1 \\
(2.2)\end{array}$ & $\begin{array}{l}1.5 \\
(0.5)\end{array}$ \\
\hline Dwayaangam cornuta Descals & $2(1)$ & - & $2(1)$ & $\begin{array}{l}8.9 \\
(4.4)\end{array}$ & $\begin{array}{l}1.2 \\
(0.9)\end{array}$ \\
\hline Helicomyces scandens Morgan & 1 & - & - & 2.2 & 0.3 \\
\hline
\end{tabular}


Table 4 Number of occurrences (out of 15 bags with leaf disks), frequency of occurrence (FO \%) and relative abundance (RA \%) of aquatic hypohomycetes on submerged leaf disks of cashew (Anacardium occidentale) during summer, monsoon and post-monsoon in Kaiga stream and Kadra dam (in parenthesis)

\begin{tabular}{|c|c|c|c|c|c|}
\hline & Summer & Monsoon & Post-monsoon & FO (\%) & $\overline{R A}(\%)$ \\
\hline Lunulospora curvula Ingold & $11(9)$ & $10(4)$ & $\begin{array}{l}15 \\
(10)\end{array}$ & $\begin{array}{l}79.9 \\
(51.1)\end{array}$ & $\begin{array}{l}16.3 \\
(25.3)\end{array}$ \\
\hline Triscelophorus acuminatus Nawawi & $9(2)$ & $8(2)$ & $9(6)$ & $\begin{array}{l}57.7 \\
(22.2)\end{array}$ & $\begin{array}{l}11.8 \\
(11.0)\end{array}$ \\
\hline $\begin{array}{l}\text { Triscelophorus konajensis K.R. Sridhar } \\
\text { \& Kaver. }\end{array}$ & $5(3)$ & $8(2)$ & $10(3)$ & $\begin{array}{l}51.1 \\
(17.8)\end{array}$ & $\begin{array}{l}10.4 \\
(8.8)\end{array}$ \\
\hline $\begin{array}{l}\text { Anguillospora longissima (Sacc. \& P. } \\
\text { Syd.) Ingold }\end{array}$ & $5(2)$ & $7(3)$ & $5(1)$ & $\begin{array}{l}37.7 \\
(13.3)\end{array}$ & $\begin{array}{l}7.7 \\
(6.6)\end{array}$ \\
\hline Campylospora chaetocladia Ranzoni & - & $5(1)$ & $8(5)$ & $\begin{array}{l}28.9 \\
(13.3)\end{array}$ & $\begin{array}{l}5.9 \\
(6.6)\end{array}$ \\
\hline Flagellospora curvula Ingold & $2(1)$ & 5 & $6(3)$ & $\begin{array}{l}28.9 \\
(8.9)\end{array}$ & $\begin{array}{l}5.9 \\
(4.4)\end{array}$ \\
\hline Triscelophorus monosporus Ingold & 4 & 3 & $8(2)$ & $\begin{array}{l}33.3 \\
(4.4)\end{array}$ & $\begin{array}{l}6.8 \\
(2.2)\end{array}$ \\
\hline Clavariana aquatica Nawawi & - & 5 & $8(3)$ & $\begin{array}{l}28.9 \\
(6.7)\end{array}$ & $\begin{array}{l}5.9 \\
(3.3)\end{array}$ \\
\hline Lunulospora cymbiformis K. Miura & $3(1)$ & 2 & $6(1)$ & $\begin{array}{l}24.4 \\
(8.9)\end{array}$ & $\begin{array}{l}5.0 \\
(2.2)\end{array}$ \\
\hline Anguillospora crassa Ingold & 2 & (3) & $5(2)$ & $\begin{array}{l}15.5 \\
(11.1)\end{array}$ & $\begin{array}{l}3.2 \\
(5.5)\end{array}$ \\
\hline Flabellowpora verticillata Alas. & - & $2(1)$ & $2(4)$ & $\begin{array}{l}8.9 \\
(11.1)\end{array}$ & $\begin{array}{l}1.8 \\
(5.5)\end{array}$ \\
\hline Tripospermum myrti (Lind) S. Hughes & (1) & 2 & $4(2)$ & $\begin{array}{l}13.3 \\
(6.7)\end{array}$ & $\begin{array}{l}2.7 \\
(3.3)\end{array}$ \\
\hline Dimorphospora foliicola Tubaki & - & - & $7(2)$ & $\begin{array}{l}15.5 \\
(4.4)\end{array}$ & $\begin{array}{l}3.2 \\
(2.2)\end{array}$ \\
\hline Clavariopsis aquatica de Wild. & 1 & - & $5(2)$ & $\begin{array}{l}13.3 \\
(4.4)\end{array}$ & $\begin{array}{l}2.7 \\
(1.1)\end{array}$ \\
\hline Flabellospora multiradiata Nawawi & - & - & $6(2)$ & $\begin{array}{l}13.3 \\
(4.4)\end{array}$ & $\begin{array}{l}2.7 \\
(2.2)\end{array}$ \\
\hline Nawawia filiformis (Nawawi) Marvanová & 2 & - & $4(1)$ & $\begin{array}{l}13.3 \\
(2.2)\end{array}$ & $\begin{array}{l}2.7 \\
(4.4)\end{array}$ \\
\hline Ingoldiella hamata D.E. Shaw & - & - & $5(2)$ & $\begin{array}{l}11.1 \\
(4.4)\end{array}$ & $\begin{array}{l}2.3 \\
(2.2)\end{array}$ \\
\hline Flabellospora crassa Alas. & - & - & $3(2)$ & $\begin{array}{l}6.7 \\
(4.4)\end{array}$ & $\begin{array}{l}1.4 \\
(2.2)\end{array}$ \\
\hline $\begin{array}{l}\text { Synnematophora constricta K.R. Sridhar } \\
\text { \& Kaver. }\end{array}$ & - & 1 & $3(1)$ & $\begin{array}{l}8.9 \\
(2.2)\end{array}$ & $\begin{array}{l}1.8 \\
(1.1)\end{array}$ \\
\hline
\end{tabular}

The initial nitrogen content was higher in banyan than cashew leaves. In both leaves and locations, the nitrogen increased. Nitrogen was elevated more quickly by attaining the highest in banyan leaves in both locations during post-monsoon. The initial total phosphorus was higher in banyan leaves than cashew leaves and decreased subsequently. Its decrease was faster (within 1 or 2 weeks) in both leaves and locations during post-monsoon than summer and monsoon seasons with subsequent increase or steady state. The initial total phenolics were higher in cashew than banyan leaves. It decreased more quickly in cashew compared to banyan leaves.

Changes in enzymes of banyan and cashew leaf during decomposition in different seasons are given Figure 4. Cellulase of banyan and cashew leaves swiftly elevated within one or two weeks in both locations. Subsequently it was stable or attained same level at the end of 56 days with an exception. Cellulase in banyan leaves gradually decreased after two weeks in stream during monsoon. Xylanase generally attained a peak within 1-4 weeks with a few exceptions (banyan in stream during summer elevated slowly; banyan in stream during monsoon attained highest on 56 
days). Pectinase in banyan showed a peak during second or fourth or eighth week. In cashew leaves, it showed a peak in two weeks (except for cashew leaves in dam during summer).

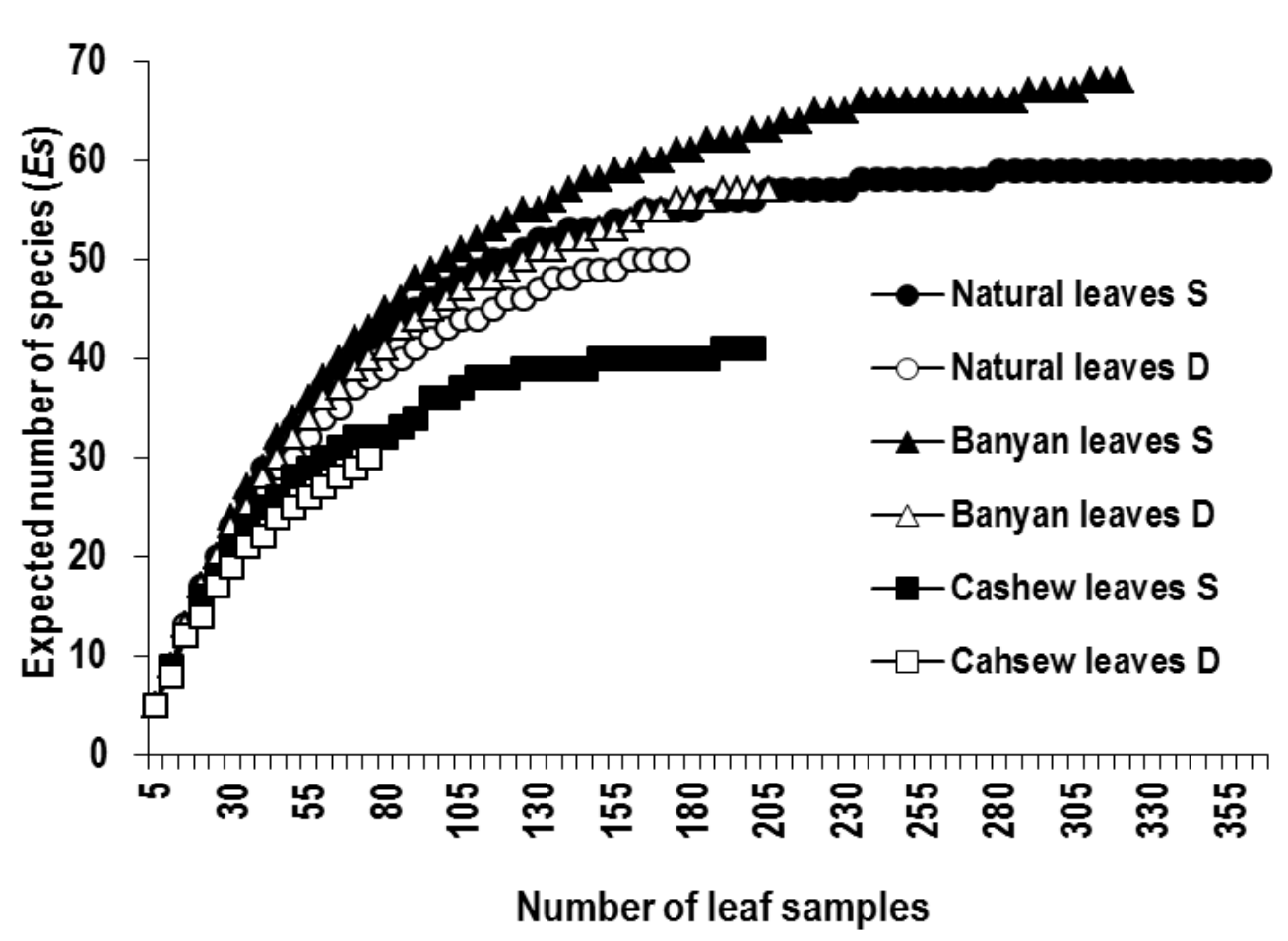

Fig. 2 - Expected number of species of aquatic hyphomycetes in natural and submerged leaf litter in Kaiga stream (S) and Kadra dam (D).

Table 5 Species richness and diversity aquatic hyphomycetes in leaf litter in Kaiga stream and Kadra dam

\begin{tabular}{lllllll}
\hline & \multicolumn{2}{c}{ Natural leaves } & \multicolumn{2}{c}{ Banyan leaves } & \multicolumn{2}{c}{ Cashew leaves } \\
\cline { 2 - 7 } & Stream & Dam & Stream & Dam & Stream & Dam \\
\hline Species richness & 23 & 23 & 28 & 27 & 19 & 19 \\
Expected number of species, $E_{(575)}{ }^{*}$ & 42 & 38 & 43 & 40 & 32 & 30 \\
Shannon diversity & 4.222 & 4.134 & 4.512 & 4.379 & 3.837 & 3.725 \\
Pielou's evenness & 0.947 & 0.914 & 0.932 & 0.911 & 0.920 & 0.877 \\
\hline
\end{tabular}

Note: *Out of isolations from 75 random leaf samples

Table 6 Sorensen's similarity index $(\%)$ of aquatic hyphomycetes in leaf litter in Kaiga stream and Kadra dam (NS, natural leaves in stream; ND, natural leaves in dam; BS, Banyan leaves in stream; $\mathrm{BD}$, Banyan leaves in dam; CS, Cashew leaves in stream; CD, Cashew leaves in dam)

\begin{tabular}{llllll}
\hline & ND & BS & BD & CS & CD \\
\hline NS & 100 & 86.3 & 80 & 90.5 & 90.5 \\
& ND & 86.3 & 88 & 90.5 & 90.5 \\
& & BS & 98.2 & 80.9 & 80.9 \\
& & & BD & 82.6 & 82.6 \\
& & & CS & 100 \\
\hline
\end{tabular}



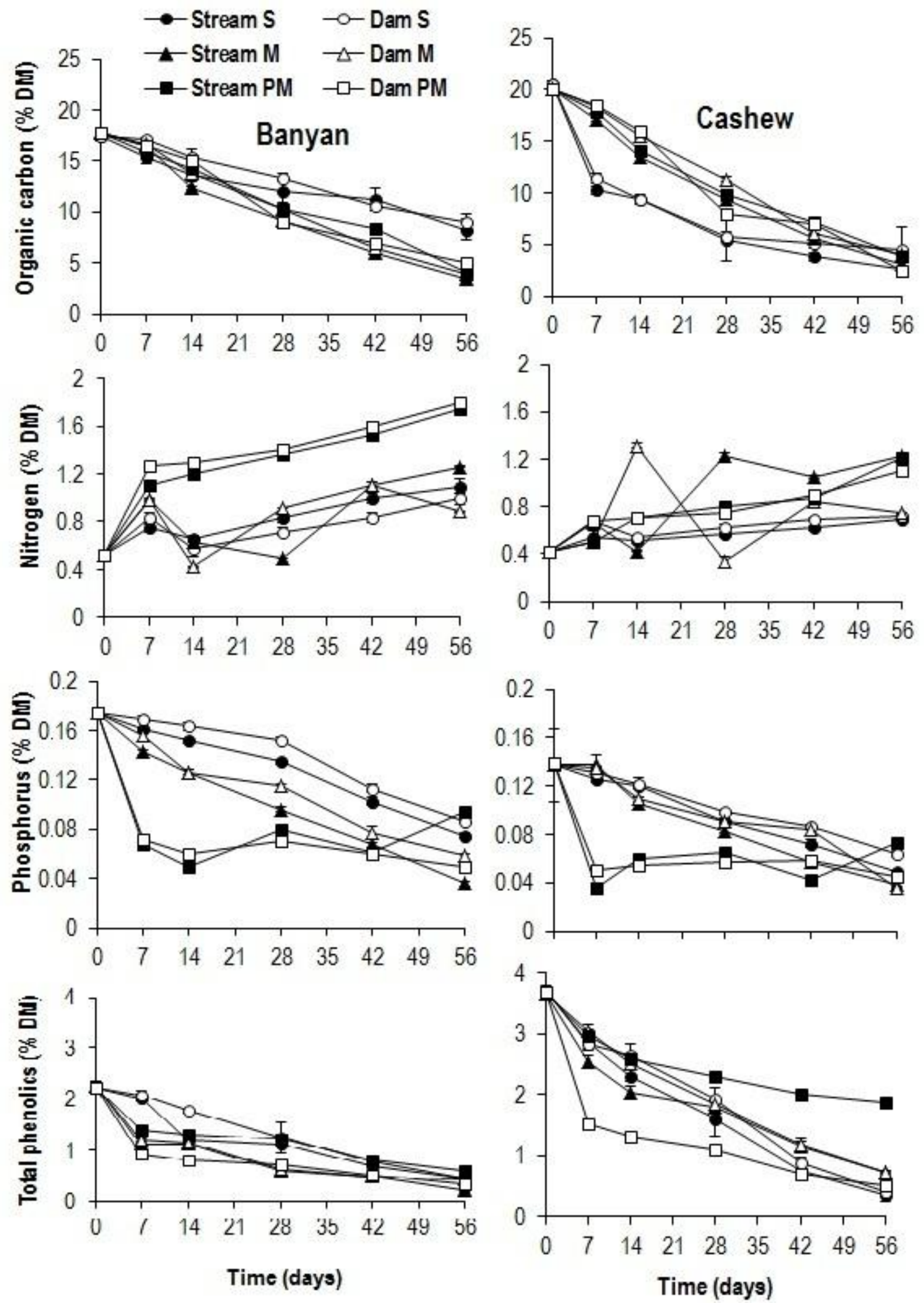

Fig. 3 - Changes in chemistry of banyan and cashew leaf litter in different seasons (S, summer; $M$, monsoon; PM, post-monsoon) in Kaiga stream and Kadra dam. 

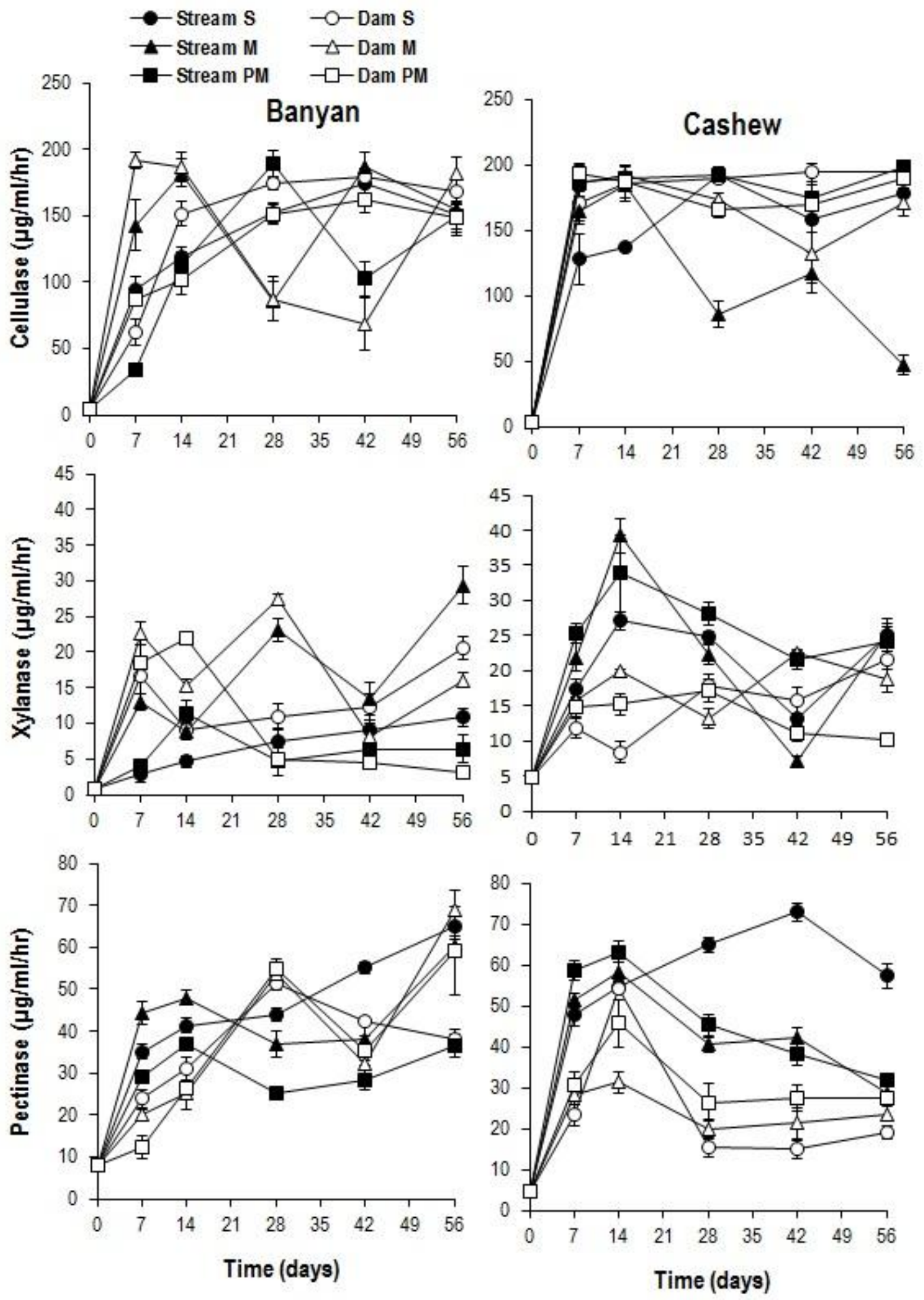

Fig. 4 - Enzyme profile of banyan and cashew leaf litter in different seasons (S, summer; M, monsoon; PM, post-monsoon) in Kaiga stream and Kadra dam. 


\section{Changes in leaf mass}

Banyan leaf mass in both locations decreased gradually with a few exceptions (Fig. 5). During summer in stream, banyan mass lost more quickly, while it was slow during post-monsoon. Except for cashew leaves during summer, rest of the samples lost mass gradually in dam.

The estimated daily exponential decay coefficient $(k)$ of banyan in stream ranged between 0.0037 (post-monsoon) and 0.0050 (monsoon), while in dam it was ranged between 0.0042 (postmonsoon) and 0.0048 (summer) (Table 7). In cashew leaves, the decay rates in stream ranged between 0.0030 (post-monsoon) and 0.0043 (monsoon), while in dam it was between 0.0032 (monsoon) and 0.0039 (summer). The decay coefficient was significantly differed in banyan leaves between stream and dam during monsoon and post-monsoon, while in cashew leaves it was significant only during monsoon ( $t$-test). The banyan leaves in stream lost $50 \%$ mass $\left(t_{50}\right)$ more quickly during monsoon (139 days) compared to summer (144 days) and post-monsoon (189 days), while in dam it was during summer (145 days) than monsoon (185 days) and post-monsoon (165 days). The $t_{50}$ of cashew leaves followed similar pattern as seen in banyan leaves.

Table 8 gives the correlation coefficients between leaf mass remaining against the changes in leaf chemistry and leaf enzymes. The banyan leaf mass was positively correlated with organic carbon $(\mathrm{p}<0.01)$, phosphorus (dam site, $\mathrm{p}<0.05)$ and total phenolics $(\mathrm{p}<0.01)$, while it was negatively correlated with nitrogen, cellulase $(p<0.05)$, xylanase and pectinase $(p<0.01)$ of both locations. The total phenolics of banyan leaves was positively correlated with organic carbon $(\mathrm{p}<0.01)$ and phosphorus $(\mathrm{p}<0.01)$, while it was negatively correlated with nitrogen (stream, $\mathrm{p}<0.05$; dam, $\mathrm{p}<0.01$ ), cellulase (stream, $\mathrm{p}<0.05$ ), xylanase (stream, $\mathrm{p}<0.01$ ) and pectinase (stream, $\mathrm{p}<0.01$; dam, $\mathrm{p}<0.05)$ in both locations. The remaining leaf mass of cashew was positively correlated with organic carbon $(\mathrm{p}<0.01)$, phosphorus (stream, $\mathrm{p}<0.01)$ and total phenolics (stream, $\mathrm{P}<0.01$; dam, $\mathrm{p}<0.05$ ), while negatively correlated with cellulase (dam, $\mathrm{p}<0.05$ ), xylanase and pectinase in both locations. The total phenolics of cashew leaves was positively correlated with organic carbon $(\mathrm{p}<0.01)$ and phosphorus (stream, $\mathrm{p}<0.05$; dam, $\mathrm{p}<0.01)$, while negatively correlated with nitrogen (dam, $\mathrm{p}<0.01$ ), cellulase, xylanase and pectinase in both locations.
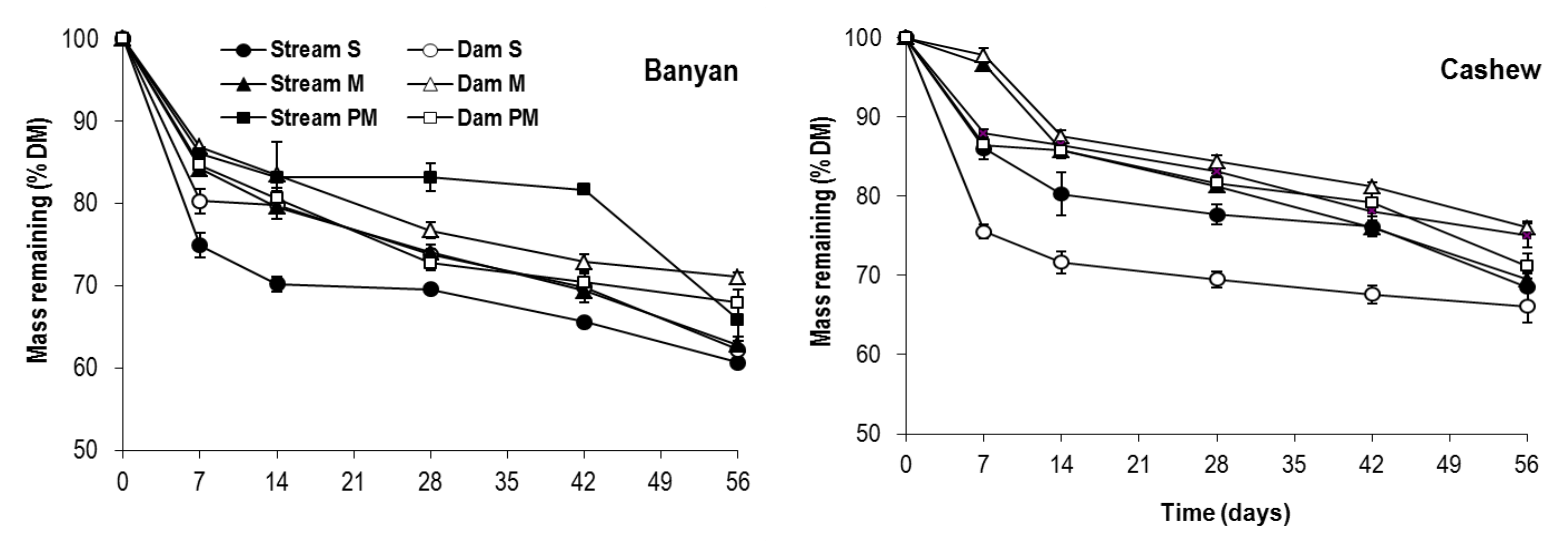

Fig. 5 - Mass loss of banyan and cashew leaf litter in different seasons (S, summer; M, monsoon; PM, post-monsoon) in Kaiga stream and Kadra dam.

\section{Discussion}

The mean water temperature was higher in Kadra dam in all seasons than Kaiga stream. The mean elevation of temperature in dam ranged between 8 and $10^{\circ} \mathrm{C}$. Temperature regime of dam is equivalent or comparable to earlier studies in discharge site of Kali River (range, $27.5-31^{\circ} \mathrm{C}$ ) (Sridhar et al. 2010a) and higher than incubation of leaf litter collected from upstream site (24$28^{\circ} \mathrm{C}$ ) of Kali River yielded 15 species of aquatic hyphomycetes and 513-520 conidia/mg (Sridhar et al. 2010a). 
Table 7 Statistics of leaf mass loss rates ( $k$, daily exponential decay rate; $R^{2}$, coefficient of determination; $t_{50}$, estimated time in days for $50 \%$ mass loss)

\begin{tabular}{lllll}
\hline & & Summer & Monsoon & Post-monsoon \\
\hline Banyan leaves & & & & \\
Kaiga stream & $k$ & $0.0048^{\mathrm{a}}$ & $0.0050^{\mathrm{a}}$ & $0.0037^{\mathrm{a}}$ \\
& $R^{2}$ & 0.579 & 0.813 & 0.755 \\
& $t_{50}$ & 144 & 139 & 189 \\
Kadra dam & $k$ & $0.0048^{\mathrm{a}}$ & $0.0038^{\mathrm{b}}$ & $0.0042^{\mathrm{b}}$ \\
& $R^{2}$ & 0.758 & 0.755 & 0.712 \\
& $t_{50}$ & 145 & 185 & 165 \\
\hline Cashew leaves & & & & \\
Kaiga stream & $k$ & $0.0037^{\mathrm{a}}$ & $0.0043^{\mathrm{a}}$ & $0.0030^{\mathrm{a}}$ \\
& $R^{2}$ & 0.718 & 0.895 & 0.789 \\
& $t_{50}$ & 189 & 161 & 234 \\
Kadra dam & $k$ & $0.0039^{\mathrm{a}}$ & $0.0032^{\mathrm{b}}$ & $0.0033^{\mathrm{a}}$ \\
& $R^{2}$ & 0.471 & 0.844 & 0.791 \\
& $t_{50}$ & 180 & 218 & 211 \\
\hline
\end{tabular}

Note: $k$ between locations with different letters indicate significant difference $(t$-test, $\mathrm{p}<0.01)$

Increase of temperature of bubble chambers to $31,33,36^{\circ} \mathrm{C}$ resulted in decreased species richness (10, 5, 2 spp., respectively) as well as conidial output (460, 105, 25 conidia/mg, respectively) and no conidia released at $38^{\circ} \mathrm{C}$. This study also corroborates with studies on aquatic hyphomycetes of two thermal springs of the Western Ghats (Chandrashekar et al. 1991b, Rajashekhar \& Kaveriappa 1996). It is necessary to simulate the conditions of the natural habitats in laboratory microcosms with dam/stream water to assess the impact of temperature and other factors on the functions of aquatic hyphomycetes (e.g. growth and sporulation). Even though aquatic hyphomycetes (vegetative phase) tolerate elevated temperatures, their sporulation (reproductive phase) potential suffers (e.g. Sridhar et al. 2010a).

The $\mathrm{pH}$ of stream and dam locations was alkaline (range, 7.1-7.8) and similar to temperature regimes of the Kali River at high altitude and low altitude locations (543 m asl, pH, 7.8; $235 \mathrm{~m}$ asl, pH 7.45; $222 \mathrm{~m}$ asl, pH 7.3; $80 \mathrm{~m}$ asl, pH 7.21-7.24) (Rajashekhar \& Kaveriappa 2003, Madoddi et al. 2009, Sridhar et al. 2010a), River Payaswini (500 m asl, pH 7.1) and River Kollur (350 m asl, $\mathrm{pH}$ 7.1) (Raviraja et al. 1998a), Sampaje stream (500 m asl, $\mathrm{pH} 7.1-7.4 ; 510 \mathrm{~m}$ asl, $\mathrm{pH} 7.2$ ) (Raviraja et al. 1996, Sridhar et al. 2010b), Bagamandala stream (560 m asl, pH 7.2), Agumbe stream (960 m asl, pH 7.2; $970 \mathrm{~m}$ asl, $\mathrm{pH} 7.4)$ and Shivpura stream (460 m asl, pH 7.3) (Sridhar et al., 2010b). The $\mathrm{pH}$ of stream and dam locations is comparable to 19 out of 21 lotic habitats of the Western Ghats (7.1-7.8 vs. 7.2-8.8) (Rajashekhar \& Kaveriappa 2003).

The dissolved oxygen in dam was lower than stream (6.5-7 vs. 8-8.3 mg/L) and an earlier study also showed low dissolved oxygen in discharge site in River Kali (3.7-5 mg/L) (Sridhar et al. 2010a). Dissolved oxygen in stream is comparable to some of the Western Ghat rivers (8-8.3 vs. 7.5-8.1 mg/L) (Maddodi et al. 2009). However, several lotic water bodies of the Western Ghats showed lower dissolved oxygen (3.3-4 mg/L) (Rajashekhar \& Kaveriappa 2003). The low dissolved oxygen (3.3-4 mg/L) resulted in low species richness compared to high dissolved oxygen (6-7 mg/L) in Western Ghat streams with positive correlation (Rajashekhar \& Kaveriappa 2003). Wood-Eggenschwiler \& Bärlocher (1983) showed significant correlations between species richness and several water parameters ( $\mathrm{pH}$, conductivity, alkalinity, calcium and magnesium concentrations). They also indicated that factors like temperature, water flow and competition among fungi are also responsible for variation in species richness. However, Bärlocher (1987) did not find any correlation between species richness and water parameters of $10 \mathrm{soft}$ water streams of eastern Canada. But, the combined data of 16 streams of France, Germany and Switzerland showed a significant negative correlation between species richness and $\mathrm{pH}$ (Wood-Eggenschwiler \& Bärlocher 1983, Bärlocher 1987). 
Table 8 Pearson correlation coefficients between leaf mass remaining vs. leaf chemistry and enzymes in Kaiga stream and Kadra dam (in parenthesis)

\begin{tabular}{|c|c|c|c|c|c|c|c|}
\hline \multicolumn{8}{|c|}{ Banyan leaves } \\
\hline & $\begin{array}{l}\text { Organic } \\
\text { Carbon }\end{array}$ & Nitrogen & Phosphorus & $\begin{array}{l}\text { Total } \\
\text { Phenolics }\end{array}$ & Cellulase & Xylanase & Pectinase \\
\hline \multirow[t]{7}{*}{$\begin{array}{l}\text { Mass } \\
\text { remaining }\end{array}$} & $\begin{array}{l}0.723 * * \\
(0.784 * *)\end{array}$ & $\begin{array}{l}-0.163 \\
(-0.454)\end{array}$ & $\begin{array}{l}0.320 \\
\left(0.587^{*}\right)\end{array}$ & $\begin{array}{l}0.767 * * \\
\left(0.748^{* *}\right)\end{array}$ & $\begin{array}{l}-0.617 * \\
(-0.536 *)\end{array}$ & $\begin{array}{l}-0.450 \\
(-0.123)\end{array}$ & $\begin{array}{l}-0.823 * * \\
(-0.731 * *)\end{array}$ \\
\hline & $\begin{array}{l}\text { Organic } \\
\text { Carbon }\end{array}$ & $\begin{array}{l}-0.489 \\
\left(-0.503^{*}\right)\end{array}$ & $\begin{array}{l}0.638 * * \\
(0.727 * *)\end{array}$ & $\begin{array}{l}0.863 * * \\
(0.822 * *)\end{array}$ & $\begin{array}{l}-0.557 * \\
(-0.353)\end{array}$ & $\begin{array}{l}-0.556^{*} \\
(0.103)\end{array}$ & $\begin{array}{l}-0.431 \\
(-0.790 * *)\end{array}$ \\
\hline & & Nitrogen & $\begin{array}{l}-0.571^{*} \\
\left(-0.773^{*} *\right)\end{array}$ & $\begin{array}{l}-0.357 \\
(-0.632 * *)\end{array}$ & $\begin{array}{l}0.241 \\
(0.063)\end{array}$ & $\begin{array}{l}-0.088 \\
(-0.255)\end{array}$ & $\begin{array}{l}-0.030 \\
(0.287)\end{array}$ \\
\hline & & & Phosphorus & $\begin{array}{l}0.656^{* *} \\
\left(0.875^{* *}\right)\end{array}$ & $\begin{array}{l}-0.278 \\
(-0.197)\end{array}$ & $\begin{array}{l}-0.530 * \\
(0.125)\end{array}$ & $\begin{array}{l}-0.279 \\
(-0.445)\end{array}$ \\
\hline & & & & $\begin{array}{l}\text { Total } \\
\text { Phenolics }\end{array}$ & $\begin{array}{l}-0.616^{*} \\
(-0.435)\end{array}$ & $\begin{array}{l}-0.700 * * \\
(-0.137)\end{array}$ & $\begin{array}{l}-0.674 * * \\
(-0.610 *)\end{array}$ \\
\hline & & & & & Cellulase & $\begin{array}{l}0.293 \\
(0.214)\end{array}$ & $\begin{array}{l}0.606^{*} \\
(0.477)\end{array}$ \\
\hline & & & & & & Xylanase & $\begin{array}{l}0.525 * \\
(0.117)\end{array}$ \\
\hline
\end{tabular}

\begin{tabular}{|c|c|c|c|c|c|c|c|}
\hline \multicolumn{8}{|c|}{ Cashew leaves } \\
\hline & $\begin{array}{l}\text { Organic } \\
\text { Carbon }\end{array}$ & Nitrogen & Phosphorus & $\begin{array}{l}\text { Total } \\
\text { Phenolics }\end{array}$ & Cellulase & Xylanase & Pectinase \\
\hline \multirow[t]{7}{*}{$\begin{array}{l}\text { Mass } \\
\text { remaining }\end{array}$} & $\begin{array}{l}0.952 * * \\
(0.760 * *)\end{array}$ & $\begin{array}{l}-0.547 * \\
\left(-0.500^{*}\right)\end{array}$ & $\begin{array}{l}0.663 * * \\
(0.368)\end{array}$ & $\begin{array}{l}0.885 * * \\
(0.619 *)\end{array}$ & $\begin{array}{l}-0.264 \\
\left(-0.537^{*}\right)\end{array}$ & $\begin{array}{l}-0.138 \\
(-0.238)\end{array}$ & $\begin{array}{l}-0.224 \\
(-0.069)\end{array}$ \\
\hline & $\begin{array}{l}\text { Organic } \\
\text { Carbon }\end{array}$ & $\begin{array}{l}-0.556^{*} \\
(-0.429)\end{array}$ & $\begin{array}{l}0.489 \\
(0.436)\end{array}$ & $\begin{array}{l}0.875^{* *} \\
\left(0.675^{* *}\right)\end{array}$ & $\begin{array}{l}-0.278 \\
(-0.357)\end{array}$ & $\begin{array}{l}0.000 \\
(-0.255)\end{array}$ & $\begin{array}{l}-0.189 \\
(0.152)\end{array}$ \\
\hline & & Nitrogen & $\begin{array}{l}-0.493 \\
(-0.653 * *)\end{array}$ & $\begin{array}{l}-0.475 \\
(-0.724 * *)\end{array}$ & $\begin{array}{l}-0.0129 \\
(0.226)\end{array}$ & $\begin{array}{c}-0.069 \\
(0.070)\end{array}$ & $\begin{array}{l}-0.335 \\
(0.057)\end{array}$ \\
\hline & & & Phosphorus & $\begin{array}{l}0.533^{*} \\
\left(0.901^{* *}\right)\end{array}$ & $\begin{array}{l}-0.160 \\
(-0.389)\end{array}$ & $\begin{array}{l}-0.177 \\
(-0.339)\end{array}$ & $\begin{array}{l}-0.155 \\
(-0.121)\end{array}$ \\
\hline & & & & $\begin{array}{l}\text { Total } \\
\text { Phenolics }\end{array}$ & $\begin{array}{l}-0.217 \\
(-0.487)\end{array}$ & $\begin{array}{l}-0.046 \\
(-0.451)\end{array}$ & $\begin{array}{l}-0.314 \\
(-0023)\end{array}$ \\
\hline & & & & & Cellulase & $\begin{array}{l}0.352 \\
(0.455)\end{array}$ & $\begin{array}{l}0.542 * \\
(0.488)\end{array}$ \\
\hline & & & & & & Xylanase & $\begin{array}{l}0.457 \\
(-0.066)\end{array}$ \\
\hline
\end{tabular}

Note: *, Correlation is significant at the 0.05 level (2-tailed)

$* *$, Correlation is significant at the 0.01 level (2-tailed)

Other parameters like total alkalinity, total hardness, silica and magnesium were least during monsoon in both locations. Rest of the parameters showed variations between seasons as well as locations. The present study reveals that at least some of the water parameters of stream and dam are not drastically different from other locations of the Western Ghats. The change in physicochemical features of the lotic waters of the Western Ghats depends on the season. Besides the changes in temperature regime, $\mathrm{pH}$, oxygen, conductivity and other chemical parameters may be governed by the periodic episodes of floods through the geologic terrain. It seems that the water chemistry will be dependent on the input of organic matter either throughout the year (evergreen) or seasonally (deciduous) as mosaic of vegetation exists in the Western Ghats. There is clear cut evidence that the water chemistry and species richness of aquatic hyphomycetes from mountain, 
mid-altitude, foot hill and coastal streams (Sridhar et al. 1992, Raviraja et al. 1998a). Natural calamities and human interference (e.g. severe monsoon, forest fire, agricultural practices, mining and input of organic matter) may influence the water chemistry and in turn the structure and functions of aquatic hyphomycetes.

Among the top six species of aquatic hyphomycetes found in the present study, five were also common in different locations of the Western Ghats (Anguillospora longissima, Flagellospora curvula, Lunulospora curvula, Triscelophorus acuminatus and T. monosporus) (Sridhar et al. 1992, Rajashekhar \& Kaveriappa 2003). Anguillospora longissima, Lunulospora curvula, Triscelophorus acuminatus and T. monosporus occurred in high frequency in different locations of Kali River (Maddodi et al. 2009) coincides with a recent study (Sridhar et al. 2010a). Among the 12 less frequent species in the present study, seven species (Clavariopsis aquatica, Dwayaangam cornuta, Flabellospora crassa, F. multiradiata, Ingoldiella hamata, Nawawia filiformis and Tricladium sp.) were also less frequent in the Western Ghats (Raviraja et al. 1998a). Clavariopsis aquatica and Nawawia filiformis occurred in low frequency in only 3-4 locations out of 21 locations of the Western Ghats (Rajashekhar \& Kaveriappa 2003). Alatospora acuminata, Clavariopsis aquatica, Flabellospora crassa, F. multiradiata, Ingoldiella hamata, Tricladium sp. and Tumularia aquatica were also less frequent in Kali River (Maddodi et al. 2009, Sridhar et al. 2010a). Bärlocher (1987) has stressed on the tolerance of some species of aquatic hyphomycetes to adverse environmental conditions. The assemblage of aquatic hyphomycetes in Kaiga stream and Kadra dam imitates other locations of the Western Ghats. Rajashekhar \& Kaveriappa (2003) specified that about 10 species of aquatic hyphomycetes (Anguillospora crassa, A. longissima, Campylospora chaetocladia, Flagellospora curvula, Helicosporium vegetum, Helicomyces roseus, Lunulospora curvula, Triscelophorus acuminatus, T. monosporus and Wiesneriomyces laurinus) tolerate adverse conditions (high $\mathrm{pH}, 8.6$ and above; low oxygen concentration, $4.0 \mathrm{mg} / \mathrm{L}$ and below; high iron content, 10.91-11.28 mg/L; hardwater, 170.0-204 mg/L). Among these, five species A. longissima, F. curvula, L. curvula, T. acuminatus and T. monosporus were also dominant in Kadra dam supports the observations of Rajashekhar \& Kaveriappa (2003).

Altogether 28 species (range, 19-28 spp.) of aquatic hyphomycetes were recovered from natural leaves, banyan and cashew leaves assessed in two locations in three seasons in Kaiga stream and Kadra dam. The range of species is comparable to 8 out of 21 Western Ghat locations (Rajashekhar \& Kaveriappa 2003). Usually the species richness and conidial output will be highest during post-monsoon in Western Ghat streams (Sridhar \& Kaveriappa 1989a, Chandrashekar et al. 1990, Sridhar et al. 1992, 2010a, Raviraja et al. 1998a). For a routine survey, evaluation of water and foam may be feasible to understand the diversity and fungal assemblage. In order to follow fungal activity and colonization in a given condition, it is necessary to evaluate the immersed leaf litter in addition to natural leaf litter. A few studies monitored aquatic hyphomycetes throughout the year in Western Ghats (Chandrashekar et al. 1990, Sridhar et al. 1989a, 2010a). Variations in water qualities and input of variety of substrates influence the aquatic hyphomycetes in the Western Ghats. There seems to be no substrate specificity in aquatic hyphomycetes, but substrate preference has been found (Sridhar et al. 1992). Usually species richness will be higher in mixed leaf litter (e.g. Sridhar \& Kaveriappa 1988, Chandrashekar et al. 1990; Sridhar et al. 1992) than immersed single leaf litter (Raviraja et al. 1996, 1998b). However, there are some exceptions, for instance: banyan (Ficus benghalensis) leaves was a preferred substrate compared to other leaf litter (e.g. banana, Musa paradisiaca; jack, Artocarpus heterophyllus) (Sridhar \& Kaveriappa 1988, 1989b). In the present study, immersed banyan leaf litter showed the highest species richness (28 spp.) as well as diversity (Shannon, 4.379-4.512) of aquatic hyphomycetes compared to naturally submerged mixed leaf litter (23 spp.) and immersed cashew leaf litter (19 spp.). Some plantation leaf litter also preferred by the aquatic hyphomycetes (e.g. coffee, Coffea arabica; rubber, Heavea brasiliensis) (Sridhar \& Kaveriappa 1988, Sridhar et al. 1992). In the present study, the Sorenson's similarity index between substrate and location did not show considerable variation. In the Western Ghats due to presence of mosaic of vegetation, the entry of mixed leaf litter in to the streams helps to maintain high diversity of aquatic hyphomycetes. Rajashekhar \& Kaveriappa (2003) demonstrated a highly 
significant positive correlation between species richness of aquatic hyphomycetes with that of riparian vegetation based on their survey of 20 streams of the Western Ghats.

A few studies are available on the leaf chemistry (Raviraja et al. 1996, 1998b) and leaf enzymes (Raviraja et al. 1998b) linked with the activities of aquatic hyphomycetes in the Western Ghats. As seen in earlier studies, the present study also reveals increase in leaf nitrogen (corroborates studies by Bärlocher 1985, Webster \& Benfield 1986) and decrease in leaf phosphorus and leaf phenolics. The nitrogen elevation was highest in Kaiga stream and Kadra dam during post-monsoon season coinciding with high species richness, conidial output and diversity especially in banyan leaf (see Table 3,5). Although phosphorus in leaf litter decreased, it is the balance between leaching and immobilization by leaf microbes. The rate of leaching was high in banyan as well as cashew during post-monsoon season in both locations. But, subsequently it was steady or increased probably due to microbial immobilization. Relatively, the total phenolics lost in cashew more slowly than banyan leaves and it is reflected in low species richness as well as diversity of aquatic hyphomycetes in cashew leaves (see Table 4, 5).

Among the three enzymes studied, cellulase was higher in banyan and cashew leaves in both locations compared to xylanase and pectinase. The enzyme activity peaked within one or two weeks and subsequently remained almost steady with a few exceptions. Such increase in enzyme activity coincided with increase in total nitrogen, decrease in total phenolics and loss of leaf mass. Petersen \& Cummins (1974) placed rates of decomposition of leaves based on daily decay coefficient $(k)$ into three groups such as 'slow' $(k<0.005)$, 'medium' $(k=0.005-0.01)$ and 'fast' $(k>0.01)$. According to this classification, the banyan and cashew leaf litter in Kaiga stream and Kadra dam falls largely under slow decomposing category in all three seasons $(k, 0.0030-0.00 .0050)$. Relatively, decomposition of banyan leaves $(k, 0.0037-0.0050)$ is faster in stream as well as dam compared to cashew leaves $(k, 0.0030-0.0043)$. Decomposition of banyan and cashew leaves in Konaje (coastal) and Sampaje (Western Ghat) streams were in medium range (0.0068-0.009) (Raviraja et al. 1996). So also the banyan leaves in polluted stretch of the River Nethravathi $(k$, 0.0066-0.0075) (Raviraja et al. 1998b). It is evident that elevation of temperature generally increases the rate of leaf decomposition (Webster \& Benfield 1986). In spite of increased water temperature in dam location compared to stream $\left(31.1-32.4\right.$ vs. $\left.21.1-25.6^{\circ} \mathrm{C}\right)$ the leaf decay rate was slow indicating the influence of some other factor/s. It is reflected in changes in leaf chemistry (slow decrease of organic carbon, phosphorus, phenolics and slow increase in nitrogen), low enzyme activity (xylanase and pectinase activity), low fungal diversity, species richness and spore output in dam location. Leaf mass of banyan and cashew was positively correlated with organic carbon, phosphorus and total phenolics, while negatively correlated with nitrogen and enzymes. Phenolics have been demonstrated to inhibit the fungal growth and delay in leaching will slow down the mass loss rates (Bärlocher et al. 1995), the delay in leaching of phenolics resulted in decreased mass loss in cashew leaves than banyan leaves in the present study. Negative correlation between phenolics and exoenzymes reveals that the mass loss was dependent on the quantity and extent of leaching of phenolics.

The richness, structural and functional attributes of aquatic hyphomycetes are dependent on input of organic matter, chemistry of substrates and water. Studies on aquatic hyphomycetes in the Western Ghats are biased due to assessment of water and foam and shallow water incubation of leaf litter. A few studies are available on quantification of conidial output using bubble chamber incubation. Similarly, chemistry, enzymes and mass loss of leaf litter have also been neglected. The present study showed that the difference in colonization of aquatic hyphomycetes in naturally submerged and deliberately submerged leaf litter in relation to water chemistry, leaf litter chemistry, enzymes and mass loss. Information on water chemistry and leaf litter chemistry documented in various locations of the Western Ghats will serve as baseline data. There is a need to continuously evaluate changes in the aquatic hyphomycetes population in selected streams of the Western Ghats at least for 4-5 years to understand the dominance or shift in core-group fungi, changes in fungal assemblages and pattern of succession (e.g. monsoon, post-monsoon and summer) to complement the temperate study (Bärlocher 2000). 


\section{Acknowledgements}

Authors are grateful to Mangalore University for permission to carry out this study at the Department of Biosciences and Nuclear Power Corporation of India Ltd. (NPCIL) Mumbai, for financial support. NMS is indebted to the NPCIL for the award of a research fellowship. Authors are thankful to Drs. H.M. Somashekarappa, University Science Instrumentation Centre, Mangalore University; S.G. Ghadge, M. Kansal, P.M. Ravi, B.N. Dileep and S.K. Singh, NPCIL, Kaiga, Karnataka for support. Authors are also thankful to Mr. Madhu S. Kandikere for statistical analysis.

\section{References}

AOAC. 1990 - Official Methods of Analysis (15 ${ }^{\text {th }}$ Edition). Association of Official Analytical Chemists, Washington DC.

APHA. 1995 - Standard Methods in Examination of Water and Waste Water (19 ${ }^{\text {th }}$ Edition). American Public Health Association, Washington DC.

Bärlocher F. 1985 - The role of fungi in the nutrition of stream invertebrates. Botanical Journal of Linnaean Society 91, 83-94.

Bärlocher F. 1987 - Aquatic hyphomycete spora in 10 streams of New Brunswick and Nova Scotia. Canadian Journal of Botany 65, 76-79.

Bärlocher F. 1992a - Research on aquatic hyphomycetes: historical background and overview. In: The Ecology of Aquatic Hyphomycetes (ed F Bärlocher), Springer-Verlag GmbH, New York, $1-15$.

Bärlocher F. 1992b - Community organization. In: The Ecology of Aquatic Hyphomycetes (ed F Bärlocher), Springer-Verlag, Berlin, 38-76.

Bärlocher F. 2000 - Water-borne conidia of aquatic hyphomycetes: seasonal and yearly patterns in Catamaran Brook, New Brunswick, Canada. Canadian Journal of Botany 78, 157-167.

Bärlocher F. 2005 - Freshwater fungal communities. The Fungal Community: Its Organization and Role in the Ecosystem ( $3^{\text {rd }}$ Edition) (eds J Dighton, Jr JF, P Oudemans), CRC Press, Boca Raton, FL, 39-59.

Bärlocher F. 2009 - Reproduction and dispersal in aquatic hyphomycetes. Mycoscience 50, 3-8.

Bärlocher F, Corkum M. 2003 - Nutrient enrichment overwhelms diversity effects in leaf decomposition by stream fungi. Oikos 101, 247-252.

Belliveau MJR, Bärlocher F. 2005 - Molecular evidence confirms multiple origins of aquatic hyphomycetes. Mycological Research 109, 1407-1417.

Bärlocher F, Canhoto C, Graça MAS. 1995 - Fungal colonization of alter and eucalypt leaves in two streams in Central Portugal. Archiv für Hydrobiologie 133, 457-470.

Carmichael JW, Kendrick WB, Conners IL, Sigler L. 1980 - Genera of Hyphomycetes. The University of Alberta Press, Edmonton, Canada.

Chale FMM. 1993 - Degradation of mangrove leaf litter under aerobic conditions. Hydrobiologia 257, 177-183.

Chandrashekar KR, Kaveriappa KM. 1991a - Production of extracellular cellulase by Lunulospora curvula and Flagellospora penicillioides. Folia Microbiologica 36, 249-255.

Chandrashekar KR, Sridhar KR, Kaveriappa KM. 1991b - Aquatic hyphomycetes of a sulphur spring. Hydrobiologia 218, 151-156.

Chandrashekar KR, Sridhar KR, Kaveriappa KM. 1990 - Periodicity of water-borne hyphomycetes in two streams of Western Ghat Forests (India). Acta Hydrochimica et Hydrobiologica 18, 187-204.

Chao A, Chazdon RL, Colwell RK, Shen T-J. 2005 - A new statistical approach for assessing similarity of species composition with incidence and abundance data. Ecology Letters 8, $148-159$.

Cummins KW, Wilzbach MA, Gates DM, Perry JB, Talaiferro WB. 1989 - Shredders and riparian vegetation. BioScience 39, 24-30. 
Dang CK, Gessner MO, Chauvet E. 2007 - Influence of conidial traits and leaf structure on attachment success of aquatic hyphomycetes on leaf litter. Mycologia 99, 24-32.

Duarte S, Pascoal C, Cássio F, Bärlocher F. 2006 - Aquatic hyphomycete diversity and identity affect leaf litter decomposition in microcosms. Oecologia 147, 658-666.

Fisher SG, Likens GE. 1973 - Energy flow in Bear Brook, New Hampshire: an integrative approach to stream ecosystem metabolism. Ecological Monograph 43, 421-439.

Gessner MO. 1997 - Fungal biomass, production and sporulation associated with particulate organic matter in streams. Limnetica 13, 33-44.

Gessner MO, Gulis V, Kuehn KA, Chauvet E, Suberkropp K. 2007 - Fungal decomposers of plant litter in aquatic ecosystems. - In: The Mycota - Microbial and Environmental Relationships (Volume IV) (eds CP Kubicek, IS Druzhinina), Springer, Berlin, 301-324.

Gulis V, Suberkropp K. 2003 - Effects of inorganic nutrients on relative contribution of fungi and bacteria to carbon flow from submerged decomposing leaf litter. Microbial Ecology 45, $11-$ 19.

Gulis V, Marvanová L, Descals E. 2005 - An illustrated key to the common temperate species of aquatic hyphomycetes. In: Methods to Study Litter Decomposition: A Practical Guide (eds MAS Graça, F Bärlocher, MO Gessner), Kluwer Academic Publishers, The Netherlands, $153-167$.

Ingold CT. 1975 - An Illustrated Guide to Aquatic and Waterborne Hyphomycetes (Fungi Imperfecti). Ambleside-Cumbria, Freshwater Biological Association Scientific Publication \# 30, UK.

Jackson ML. 1973 - Soil Chemical Analysis. Prentice-Hall International, USA, pp. 498.

Jones EBG. 2006 - Form and function of fungal spore appendages. Mycoscience 47, 167-183.

Kearns SG, Bärlocher F. 2008 - Leaf surface roughness influences colonization success of aquatic hyphomycete conidia. Fungal Ecology 1, 13-18.

Krauss G-J, Solé M, Krauss G, Schlosser D, Wesenberg D, Bärlocher F. 2011 - Fungi in freshwaters: ecology, physiology and biochemical potential. FEMS Microbiology Reviews $35,620-651$.

Ludwig JA, Reynolds JF. 1988 - Statistical Ecology: A Primer on Methods and Computing. Wiley, New York.

Maddodi ND, Raviraja NS, Rajashekhar M. 2009 - Diversity of aquatic hyphomycetes of the Western Ghat rivers. In: Frontiers of Fungal Ecology, Diversity and Metabolites, IK International Publishing House Pvt. Ltd., New Delhi, 17-27.

Magurran AE. 1988 - Ecological Diversity and its Measurement. Princeton University Press, New Jersey

Marvanová L. 1997 - Freshwater hyphomycetes: A survey with remarks on tropical taxa. In: Tropical Mycology (eds KK Janardhanan, C Rajendran, K Natarajan, DL Hawksworth), Science Publishers, New York, 169-226.

Methvin BR, Suberkropp K. 2003 - Annual production of leaf decaying fungi in 2 streams. Journal of North American Benthological Society 22, 554-564.

Minshall GW. 1967 - Role of allochthonous detritus in the trophic structure of a woodland springbrook community. Ecology 48, 139-149.

Nawawi A. 1985 - Aquatic hyphomycetes and other water-borne fungi from Malaysia. Malaysian Nature Journal 39, 75-134.

Nelson N. 1944 - A photometric adaptation of the Somogyi method for the determination of glucose. Journal of Biological Chemistry 152, 375-380.

Petersen RC, Cummins KW. 1974 - Leaf processing in woodland stream. Freshwater Biology 4, 343-368.

Pielou FD. 1975 - Ecological Diversity. Wiley InterScience, New York.

Rajashekhar M, Kaveriappa KM. 1996 - Studies on the aquatic hyphomycetes of a sulphur spring in the Western Ghats, India. Microbial Ecology 32, 73-80. 
Rajashekhar M, Kaveriappa KM. 2003 - Diversity of aquatic hyphomycetes in the aquatic ecosystems of the Western Ghats of India. Hydrobiologia 501, 167-177.

Raviraja NS, Sridhar KR, Bärlocher F. 1996 - Breakdown of introduced and native leaves in two Indian streams. International Revew Gesamten Hydrobiologie 81, 529-539.

Raviraja NS, Sridhar KR, Bärlocher F. 1998a - Fungal species richness in Western Ghat streams, (Southern India); is it related to $\mathrm{pH}$, temperature or altitude? Fungal Diversity 1, 179-191.

Raviraja NS, Sridhar KR, Bärlocher F. 1998b -Breakdown of Ficus and Eucalyptus leaves in an organically polluted river in India: fungal diversity and ecological functions. Freshwater Biology 39, 537-545.

Read SJ, Moss ST, Jones EBG. 1992 - Attachment and germination of conidia. In: The Ecology of Aquatic Hyphomycetes (ed F Bärlocher), Springer-Verlag, Germany, 135-151.

Rosset J, Bärlocher F, Oertli JJ. 1982 - Decomposition of conifer needles and deciduous leaves in two Black Forest and two Swiss Jura streams. International Revew Gesamten Hydrobiologie 67, 695-711.

Santos-Flores C, Betancourt-López C. 1997 -Aquatic and Water-Borne Hyphomycetes (Deuteromycotina) in Streams of Puerto Rico. University of Puerto Rico, Puerto Rico, Caribbean Journal of Science Special Publication \# 2.

Somogyi M. 1952 - Notes on sugar determination. Journal of Biological Chemistry 195: 19-23.

Sridhar KR, Kaveriappa KM. 1988 - Colonization of leaf litter by aquatic hyphomycetes in a tropical stream. Archiv für Hydrobiologie 112, 627-630.

Sridhar KR, Kaveriappa KM. 1989a - Observations on aquatic hyphomycetes of the Western Ghat streams. Nova Hedwigia 49, 455-467.

Sridhar KR, Kaveriappa KM. 1989b - Colonization of leaves by water-borne hyphomycetes in a tropical stream. Mycological Research 92, 392-396.

Sridhar KR, Chandrashekar KR, Kaveriappa KM. 1992 - Research on the Indian Subcontinent. In: The Ecology of Aquatic Hyphomycetes (Ed. Bärlocher F). Springer-Verlag, Berlin, 182211.

Sridhar KR, Arun AB, Maria GL, Madhyastha MN. 2010a - Diversity of fungi on submerged leaf and woody litter in River Kali, Southwest India. Environmental Research Journal 5, 701714.

Sridhar KR, Karamchand KS, Hyde KD. 2010b - Wood-inhabiting filamentous fungi in 12 high altitude streams of the Western Ghats by damp incubation and bubble chamber incubation. Mycoscience 51, 104-115.

StatSoft Inc. 2008 - Statistica, Version 8. StatSoft, Tulsa, Oklahoma, USA.

Suberkropp K. 1995 - The influence of nutrients on fungal growth, productivity, and sporulation during leaf breakdown in streams. Canadian Journal of Botany 73, 1361-1369.

Triska FJ, Cromack Jr FJ. 1980 - The role of wood debris in forests and streams. In: Forests: Fresh Perspectives from Ecosystem Analysis (ed RH Waring), Oregon State University Press, Corvallis, 171-190.

Webster J. 1959 - Experiments with spores of aquatic hyphomycetes: I. Sedimentation, and impaction on smooth surfaces. Annals of Botany 23, 595-611.

Webster J, Descals E. 1981 - Morphology, distribution and ecology of conidial fungi in freshwater habitats. In: Biology of Conidial Fungi (Volume 1) (eds GT Cole, B Kendrick), Academic Press Inc, New York, 295-355.

Webster JR, Benfield EF. 1986 - Vascular plant breakdown in freshwater ecosystems. Annual Review of Ecology and Systematics 17, 567-594.

Weyers HS, Suberkropp K. 1996 - Fungal and bacterial production during the breakdown of yellow poplar leaves in 2 streams. Journal of North American Benthological Society 15, 408-420.

Wood-Eggenschwiler S, Bärlocher 1983 - Aquatic hyphomycetes in sixteen streams in France, Germany and Switzerland. Transactions of the British Mycological Society 81, 371-379. 